\title{
Un sitio de extracción de mármol para hacer brazaletes: la cantera neolítica de Cortijo Cevico (Ventorros de San José- Loja, Granada)*
}

\author{
A marble extraction site for bracelet manufacture: the Neolithic quarry of Cortijo Cevico \\ (Ventorros de San José-Loja, Granada)
}

\author{
Francisco Martínez-Sevilla ${ }^{a}$, Javier Carrasco Rus ${ }^{a}$, José Antonio Lozano Rodríguez ${ }^{\mathrm{b}}$, \\ Francisca Jiménez-Cobos ${ }^{\mathfrak{c}}$ y Mario Gutiérrez Rodríguez ${ }^{\mathfrak{a}}$
}

\section{RESUMEN}

Los brazaletes de piedra del Neolítico Antiguo ( $c a$. $5500-4800 \mathrm{cal}$ AC) y los contextos donde se produjeron son relativamente conocidos. Sin embargo, lugares únicamente destinados a la extracción de materia prima y primera transformación no se han documentado en la Península Ibérica. En este trabajo damos a conocer la primera cantera de mármol para la elaboración de preformas para brazaletes. Se presentan los resultados de prospección y excavación en la cantera de Cortijo Cevico (Ventorros de San José-Loja, Granada). El estudio geológico regional y de la materia prima, así como los análisis tecnológicos, estadísticos y experimentales nos permiten reconocer cómo funcionó la explotación y arrojar luz sobre la organización social de las primeras comunidades agropecuarias.

\begin{abstract}
Stone bracelets of the Early Neolithic (ca. 5500-4800 cal BC) and their production workshops are well documented. Until now, extraction and primary reduction sites were not known from the Iberian Peninsula. This paper presents the survey and excavation of the first marble quarry for the knapping of bracelet preforms in this region, at Cortijo
\end{abstract}

Cevico (Ventorros de San José-Loja, Granada). The regional geological study and raw material characterization, as well as the technological, statistical and experimental analyses, allow us to recognize how exploitation worked, and shed light on the social organization of the first farming communities.

Palabras clave: Brazaletes de piedra; Mármol dolomítico; Cantería prehistórica; Neolítico Antiguo; Península Ibérica.

Key words: Stone bracelets; Dolomitic marble; Prehistoric quarrying; Early Neolithic; Iberian Peninsula.

\section{INTRODUCCIÓN}

Los contextos de aprovechamiento de fuentes de materia prima ofrecen una información muy relevante sobre el comportamiento de las sociedades de la Prehistoria. El estudio de lugares de adquisición de litologías usadas en actividades cotidianas es de vital importancia para entender la organización social y las relaciones intergrupales mediante intercambios. Las minas y canteras de rocas empleadas en adornos tienen un valor añadido, ya que esos elementos no se relacionan con las actividades subsistenciales, sino que

* Las excavaciones han sido financiadas por el grupo de investigación HUM-143 de la Junta de Andalucía y el Dpto. de Prehistoria y Arqueología de la Universidad de Granada. F. Martínez-Sevilla es contratado del Plan Propio de Perfeccionamiento de Doctores de la Universidad de Granada, desarrollando su trabajo en el Dept. of Archaeology. Durham University (UK).

${ }^{a}$ Dpto. Prehistoria y Arqueología. Universidad de Granada. Facultad de Filosofía y Letras. Campus Cartuja s/n 18071 Granada.

Correos e.: martinezsevilla@ugr.es https://orcid.org/0000-0002-1385-3585; jcrus@ugr.es https://orcid.org/0000-0002-4912-2258; mgrodriguez@ugr.es https://orcid.org/0000-0003-2045-1493

b Instituto Andaluz de Ciencias de la Tierra. CSIC-Universidad de Granada. Av. de las Palmeras 4, 18100 Armilla, Granada. Correo e.: jalozano@ugr.es https://orcid.org/0000-0003-4598-4472

` Museo Arqueológico Ulia. C/ Juan Pedro Carmona 4. 14530 Montemayor. Córdoba. Correo e.: franciscajimenezcobos@gmail.com https://orcid.org/0000-0003-2154-2389

Recibido 9-III-2018; aceptado 28-V-2018. 
son una expresión cultural con códigos de significado sociales (Castro 1990).

El uso de brazaletes de piedra caracteriza las primeras sociedades neolíticas en el Mediterráneo occidental. Son bien conocidos en el norte de Italia (Pétrequin et al. 2015), en el interior de Francia y Bélgica (Fromont 2013) y la costa atlántica francesa (Pailler 2007). De la misma forma, en la Península Ibérica son uno de los adornos más específicos del Neolítico Antiguo en el mediodía peninsular, considerándose un marcador cultural del inicio de este periodo (Martínez-Sevilla 2016). La distribución geográfica de los tipos de brazaletes y los talleres define dos grandes concentraciones: una en Andalucía y otra en el Levante, siendo poco representativos en el resto de la península (Fig. 1).

La elaboración de los brazaletes de mármol es un proceso complejo que conlleva la concatenación de diversas técnicas (Fig. 2) (Martínez-Sevilla 2013). Los altos índices de fractura en esta artesanía han permitido que se conserven numerosos desechos donde se elaboraban. Los talleres se ubican en el sur peninsular (Martínez-Sevilla 2014) fundamentalmente en asentamientos al aire libre, como Cabecicos Negros (Vera, Almería) (Goñi et al. 1999) o el poblado de Los Castillejos (Montefrío, Granada) (Martínez-Sevilla 2016: 154), pero también en cuevas como la de Los Mármoles (Priego de Córdoba) (Martínez-Sevilla 2010) o La Serreta (Cieza, Murcia) (Martínez-Sevilla y Salmerón 2014). Los desechos de la producción son fácilmente reconocibles en estos talleres. Sin embargo, las canteras de extracción son complejas de localizar. En Europa solo se conoce una cantera de esquistos en la Baja Normandía (Fromont et al. 2006) y afloramientos de piedras verdes (jade, serpentinitas y anfibolitas) en los

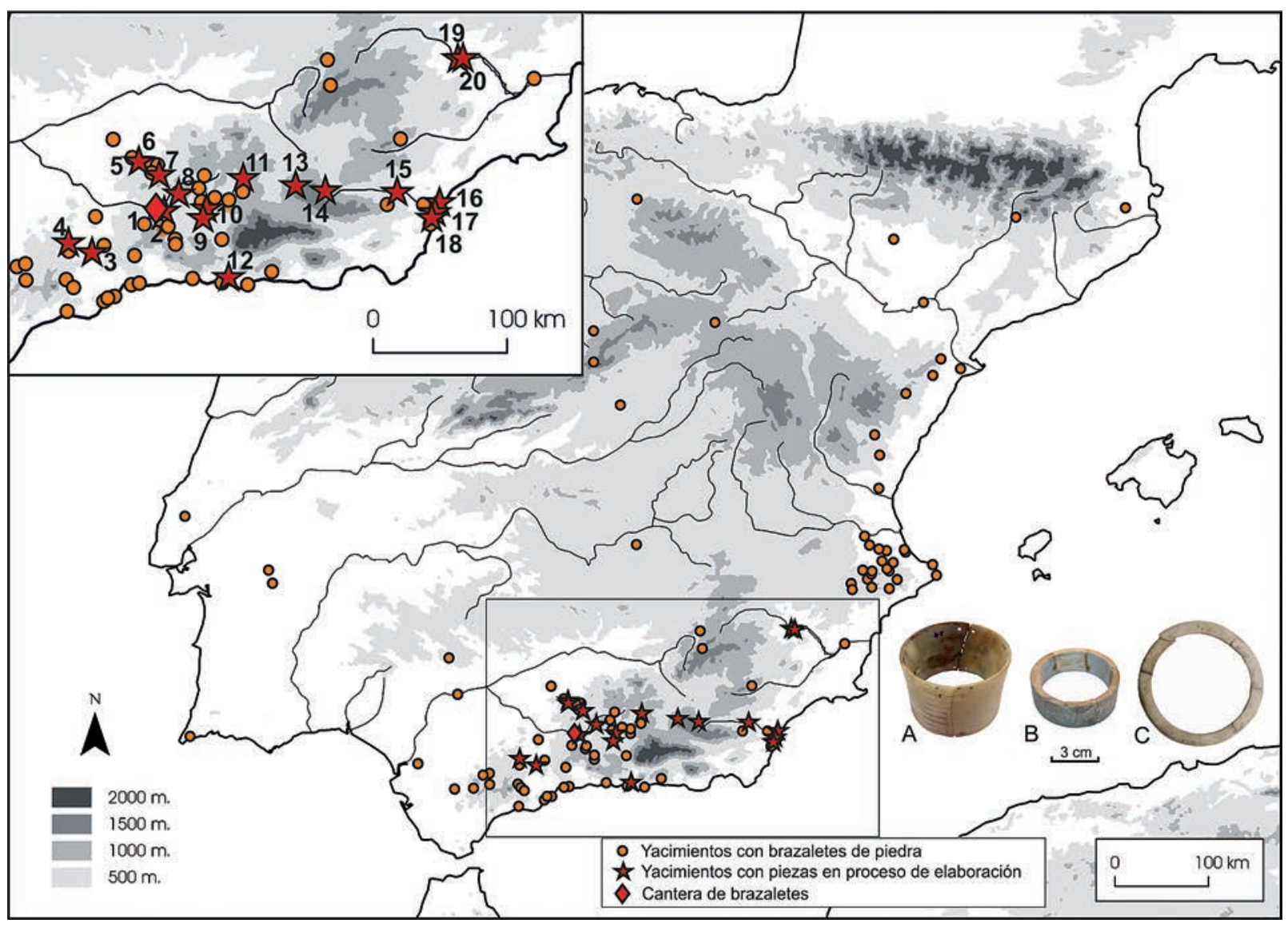

Fig. 1. Distribución de brazaletes de piedra neolíticos en la Península Ibérica y yacimientos con restos de producción de brazaletes. A. Brazaletes anchos, B. Medios y C. Estrechos: 1. Cantera de Cortijo Cevico y 2. Cortijo Higuera Alta (Ventorros de San José-Loja, Granada); 3. Valle de Abdalajis (Málaga); 4. Llano Espada (Teba, Málaga); 5. Cueva de los Murciélagos y 6. Las Piedras Viñaeras (Zuheros, Córdoba); 7. Cueva de los Mármoles (Priego de Córdoba); Granada: 8. Los Castillejos (Montefrío); 9. Las Catorce Fanegas (Chauchina); 10. La Molaina (Pinos Puente); 11. Cueva de la Carigüela (Piñar); 12. El Vínculo (Lobres); 13. Las Angosturas (Gor); 14. Cueva de la Pastora (Caniles); Almería: 15. Cerro Almanzora (Cantoria); 16. Las Palas y la Hera (Herrerías), 17. Cerro Virtud (Cuevas de Almanzora), 18. Cabecicos Negros (Vera); Murcia: 19. Abrigos del Pozo (Calasparra) y 20. Cueva-Sima de la Serreta (Cieza) (en color en la edición electrónica). 


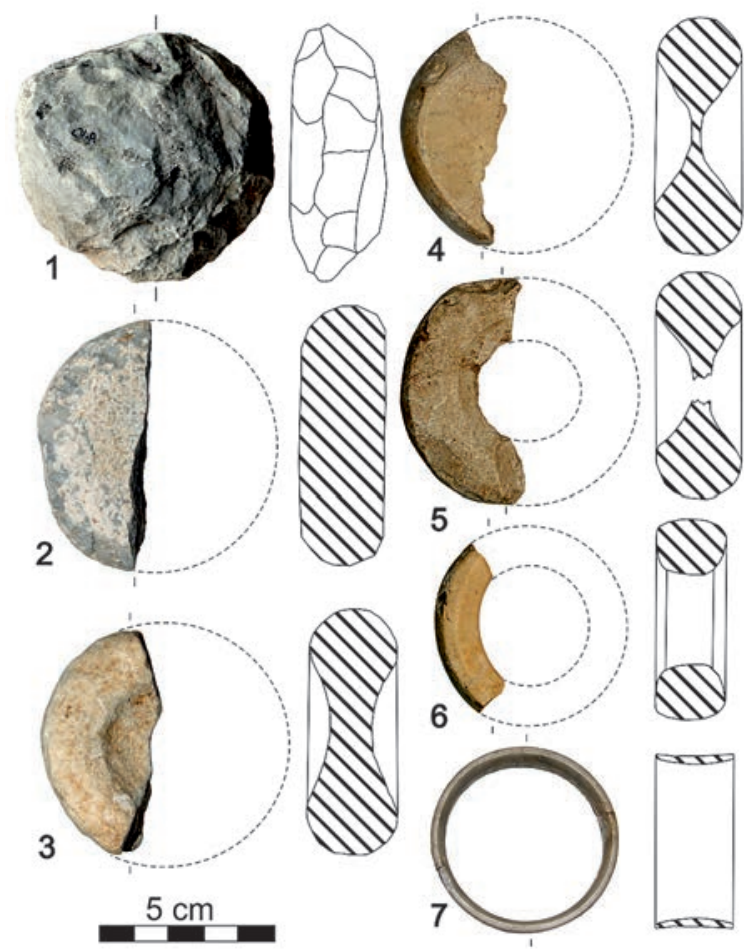

Fig. 2. Cadena operativa de elaboración de brazaletes de mármol a partir de piezas de diferentes talleres. 1. Preforma tallada (Cantera de Cortijo Cevico, Ventorros de San José-Loja, Granada); 2. Regularización mediante abujardado en la parte exterior (Las Catorce Fanegas, Chauchina, Granada); 3. Configuración de la concavidad interior con abujardado (Llano Espada, Teba, Málaga); 4. Concavidad agrandada con abrasión (Cueva de los Mármoles, Priego de Córdoba); 5. Perforación interior con percusión indirecta (Cueva de los Mármoles); 6. Reducción interior y exterior con abrasión (Cueva de los Mármoles) y 7. Pulido y producto final (Cueva de los Botijos, Benalmádena, Málaga) (en color en la edición electrónica).

entornos del Mont Viso en los Alpes italianos (Pétrequin et al. 2015, 2017). En el Neolítico Antiguo en la Península Ibérica se ha identificado la explotación de fuentes geológicas para la extracción de sílex (Consuegra et al. 2004) y de rocas tenaces como ofitas (Morgado y Lozano 2011) o eclogitas (Lozano et al. 2017), pero no canteras para adornos. Cortijo Cevico es el único yacimiento de este tipo documentado en la península por el momento.

\section{CONTEXTO GEOGRÁFICO, GEOLÓGICO Y ARQUEOLÓGICO}

La cantera de Cortijo Cevico se ubica en el poniente de Granada, a unos cuatro kilómetros al oeste de la pedanía de Ventorros de San José (Loja, Granada). Se emplaza en la vertiente derecha del río Genil, en la parte más elevada de la cuenca a $790 \mathrm{~m} \mathrm{~s} . \mathrm{n}$. m. (coordenadas UTM: 30S 396127, 4120470) (Fig. 3B). El yacimiento se sitúa en un punto central entre las densidades más destacadas de brazaletes de la Península Ibérica, hacia el sur la comarca de los Montes de Málaga y su costa, y al norte, el Subbético de la provincia de Córdoba (Fig. 1).

Desde el punto de vista geológico, la explotación se llevó a cabo sobre bloques de mármoles calizos y dolomíticos micríticos de la Formación Cehegín dentro del Muschelkalk (Triásico Medio), inmersos en una mélange tectono-sedimentaria formada fundamentalmente por arcillas, yesos, margas y areniscas del Keuper (Triásico Superior) (Sanz de Galdeano et al. 2008) (Fig. 3A). En concreto, los bloques de origen corresponden a las facies B de la Formación Cehegín que, según Pérez-Valera (2005), están compuestas fundamentalmente por calizas laminadas. Existen, justo por debajo de la serie estratigráfica, unas facies A de dolomías oscuras (Fig. 3B). Las facies B se organizan en estratos de espesores decimétricos a métricos, oscilando su espesor entre 2-12 m. Los carbonatos están compuestos por calizas oscuras micríticas, finamente laminadas, con algunas intercalaciones de grainstones bioclásticos con intraclastos. Las laminaciones corresponden por lo general, a mallas de algas (algal mats), y a veces a estructuras estromatolíticas en domos. También se reconocen laminaciones paralelas y niveles bioclásticos muy delgados, con bases erosivas y que en ocasiones incorporan clastos de sedimento carbonatado litificado (mud chips). Además hay pseudomorfos de evaporitas. Estas características son propias de carbonatos generados en ambientes inter- y supra-mareales, debido a la acción de cianobacterias, donde esporádicamente se observan episodios energéticos, debidos a tormentas, que generan depósitos de más alta energía con removilización de clastos previamente litificados. Alternan con otros de menor energía donde el sedimento puede ser bioturbado o donde se instalan cianobacterias que desarrollan bindstones (Fig. 4). El hecho de encontrarse estos bloques de diferente tamaño inmersos en una matriz de arcillas, yesos margosos y arenas, los preserva de los procesos de fracturación provocados por la Tectónica Alpina. Esto confiere a este afloramiento unas características excelentes para la cantería y la posterior talla.

El afloramiento de Cortijo Cevico está en una zona con alta concentración de yacimientos arqueológicos (Carrasco et al. 1986). El de mayor envergadura es Sierra Martilla, ubicado a $1 \mathrm{~km}$ en línea recta. Se trata de un poblado asociado a una necrópolis megalítica de tipo mixto. La ocupación prehistórica comprende dos fases: Martilla I, adscrita al Neolítico, y Martilla II al Cobre Antiguo (Carrasco et al. 2011). Además han aparecido materiales prehistóricos líticos tallados y pulidos en la vaguada que ocupa el Cortijo Cevico, situado también a 

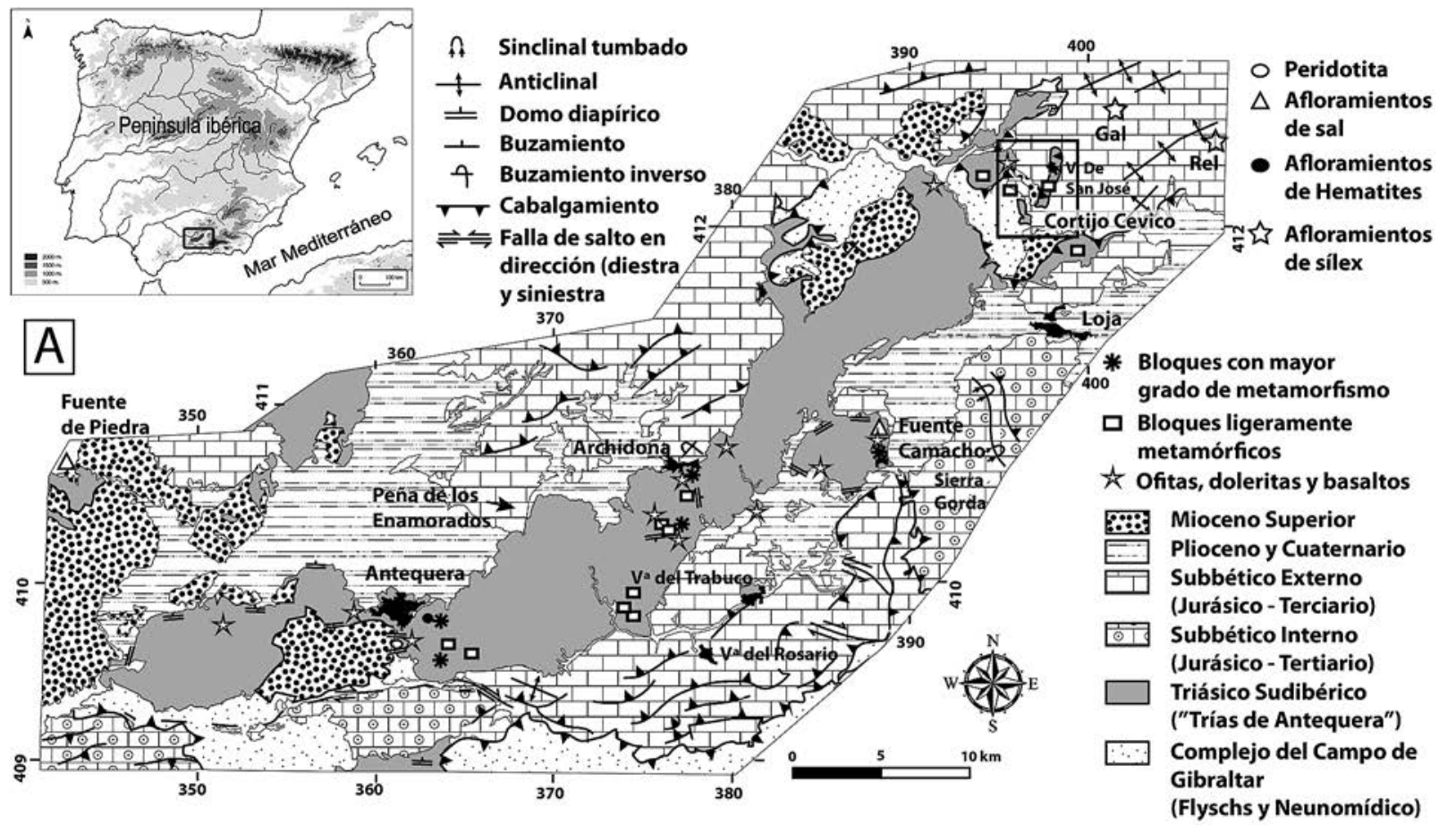

B "Trías de Antequera"

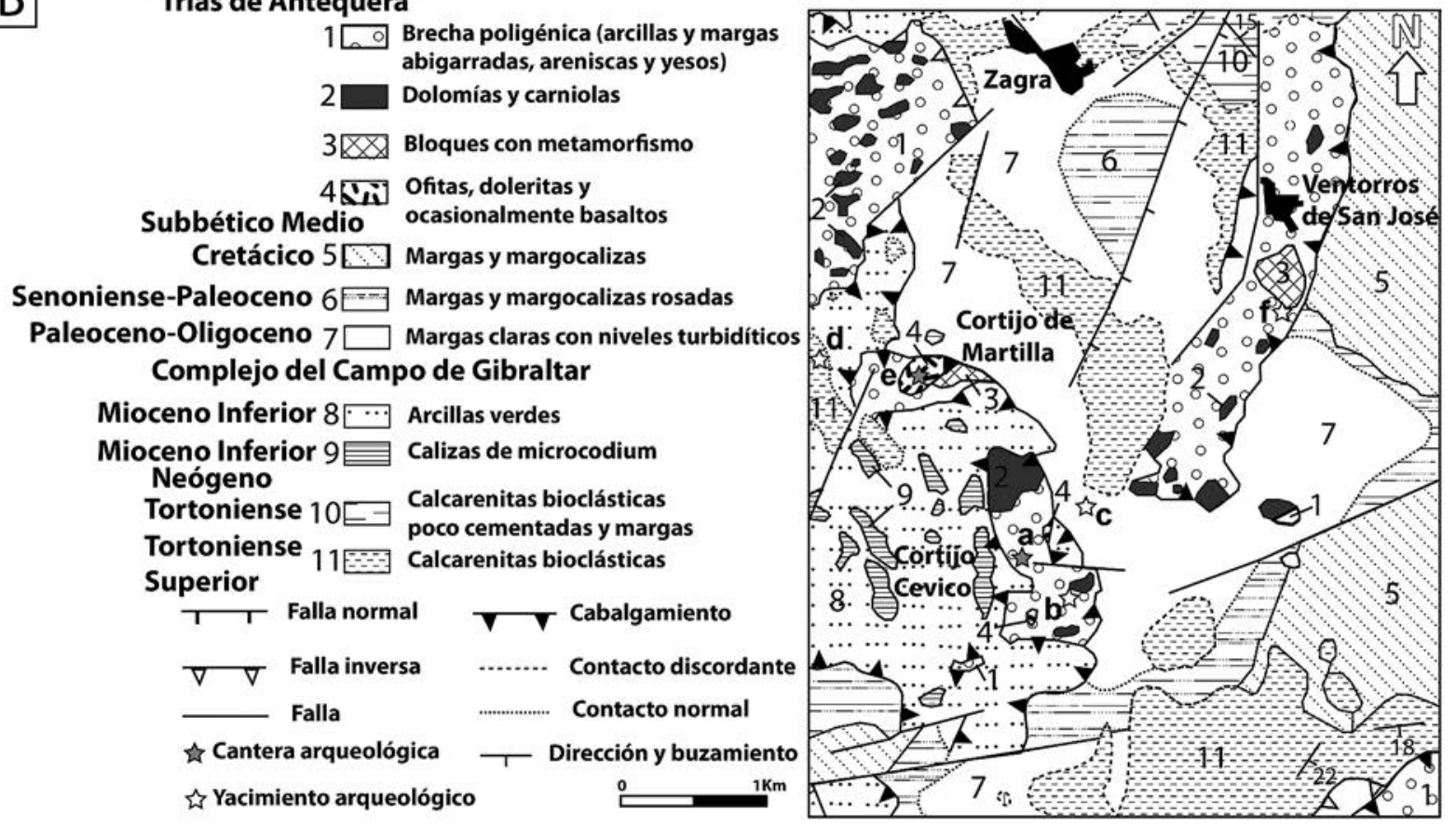

Fig. 3. Mapa geológico del área donde se localiza la cantera de Cortijo Cevico: A. Contexto geológico regional "Trías de Antequera" y materiales que los rodean (modificado a partir de Sanz de Galdeano et al. 2008); B. Contexto geológico y arqueológico local: a cantera de Cortijo Cevico, b Cortijo Higuera Alta, c Cortijo Cevico, d Sierra Martilla, e cantera de ofitas Cortijo Martilla, f Cerro del Moro. Abreviaturas: Gal. Gallumbares, Rel. Reloj, Va. Villanueva. Fuente: Modelo Digital del Terreno de Andalucía. 

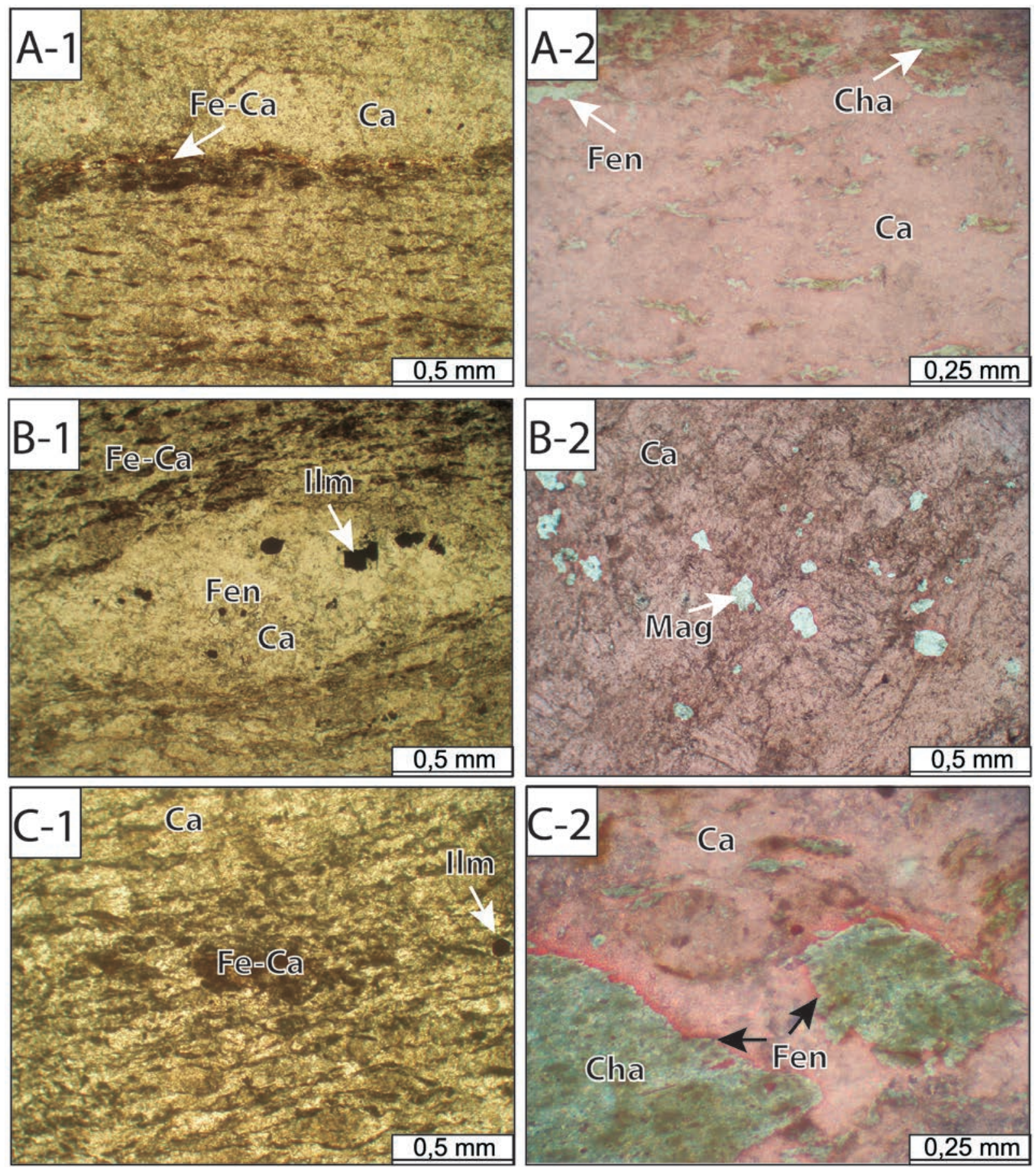

Fig. 4. Microfotografías sin nicoles cruzados de láminas delgadas de mármoles calizos micríticos procedentes de la cantera de Cortijo Cevico. La textura es grainstone y bindstones, con laminaciones fenestrales como resultado de la descomposición de materia orgánica asociada con estromatolitos algales. En ocasiones las fenestras (Fen) están rellenas de un barro de chamosita (Cha) (A-2 y C-2). Son carbonatos (Ca) generados en ambientes inter- y supra-mareales, debido a la acción de cianobacterias. También presentan carbonatos de hierro (Fe-Ca) (A-1, B-1 y C-1), mineralizaciones de ilmenita (Ilm) (B-1 y C-1) y pequeños cristales granulares de magnesita (CO3Mg) (B-2). Las microfotografías de la columna de la derecha muestran un sector de la lámina delgada teñido de parafina y que genera tonalidades propias de la calcita (en color en la edición electrónica).

Trab. Prehist., 75, N. ${ }^{\circ} 2$, julio-diciembre 2018, pp. 344-360, ISSN: 0082-5638

https://doi.org/10.3989/tp.2018.12220 
$1 \mathrm{~km}$ de la cantera y epónimo de esta ${ }^{1}$. En la prospección de los entornos del afloramiento hemos documentado brazaletes en proceso de elaboración en Cortijo de Higuera Alta, situado a unos $600 \mathrm{~m}$ al este de la cantera y en el Cerro del Moro, un gran bloque geológico de mármol que alberga una cantera contemporánea que ha enmascarado los posibles restos de aprovechamiento prehistórico (Fig. 3B). La importancia de la geología regional donde se ubica la cantera queda patente por los numerosos recursos abióticos. Entre las materias primas situadas en los entornos de la cantera destacan el sílex (Morgado et al. 2011), las ofitas para la elaboración de hachas pulimentadas cerca de Sierra Martilla (Morgado y Lozano 2011) y la sal (Terán y Morgado 2011).

La ausencia de restos orgánicos en los niveles arqueosedimentarios de la cantera no ha permitido la datación directa por métodos radiométricos. Para la contextualización cronológica de la producción de brazaletes y de la cantera, hemos seleccionado 6 talleres, asociados a unidades estratigráficas y dataciones absolutas (Tab. 1). Su localización es representativa del área geográfica de distribución de los brazaletes en el sur peninsular (Fig. 1): 1) los Abrigos del Pozo, los más orientales, en el valle del río Segura (Murcia), ofrecieron brazaletes en proceso asociados al Nivel VI del Neolítico Antiguo (Martínez Sánchez 1994). En el sureste, en la cuenca de Vera (Almería), 2) el asentamiento de Cabecicos Negros tiene un contexto exclusivo de elaboración de adornos (Goñi et al. 1999; Camalich y Martín 2013) y 3) en el de Cerro Virtud, los brazaletes se asocian a la Fase I que es anterior, tras un hiato temporal, a la sepultura colectiva del Neolítico Reciente (Montero y Ruíz 1996; Ruíz y Montero 1999). En el poniente de Granada, 4) en el asentamiento de Los Castillejos estos adornos se sitúan entre la Fase 1 y la $11 \mathrm{~b}$ de una amplia secuencia estratigráfica. Las fases se atribuyen al Neolítico Antiguo y Medio (Cámara et al. 2016) y anteceden a una fase de abandono del poblado (Molina et al. 2017). Finalmente, en la Subbética cordobesa, en la parte más occidental, 5) en la cueva de Los Mármoles se documenta toda la cadena operativa (Martínez-Sevilla 2010), asociada con materiales de fases del Neolítico Antiguo (Peña-Chocarro et al. 2013) y 6) en la de Los Murciélagos se han identificado piezas en proceso de elaboración y finalizadas atribuidas a las fases del Neolítico Antiguo (Vera y Martínez 2012).

Las 37 dataciones absolutas de estos contextos estratigráficos se sitúan entre $c a$. 5500-4800 cal AC, excluyendo un valor atípico de la Fase 5 (Ua36211) de la secuencia de Los Castillejos en clara discordancia con las demás dataciones de la fase (Fig. 5). En

\footnotetext{
1 Gámiz Jiménez, J. 1996: Bases documentales para el estudio del poblamiento neolítico y de la Edad del Cobre en la tierra de Loja. Tesis Doctoral inédita. Universidad de Granada.
}

suma, la cronología de la artesanía de los brazaletes y su restringido uso permiten situar la explotación de la cantera en el Neolítico Antiguo (ca. 5500-4800 cal AC) (Carrasco y Martínez-Sevilla 2014; Martínez-Sevilla 2016: 497; Martín-Socas et al. 2018).

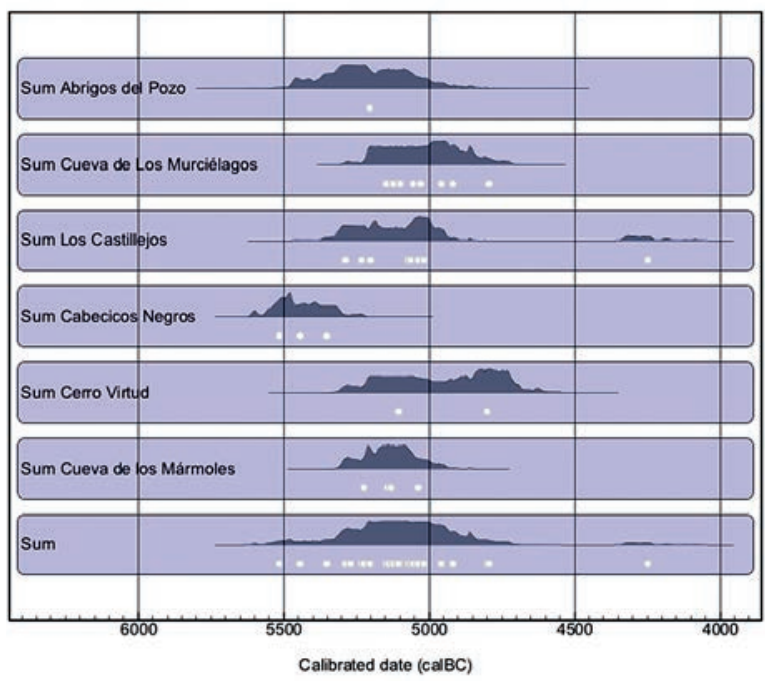

Fig. 5. Sumas probabilísticas de dataciones procedentes de yacimientos arqueológicos del sureste de la Península Ibérica con brazaletes en proceso de elaboración y asociados a unidades estratigráficas. Los puntos blancos representan la media de cada datación. En la tabla 1 se recogen las dataciones y sus contextos estratigráficos. En las muestras procedentes de conchas se ha incluido la fecha con la corrección oceánica. Elaborado con el programa de calibración OxCal v4.3.2 (Bronk Ramsey 2017) curva atmosférica internacional IntCal13 (Reimer et al. 2013) (en color en la edición electrónica).

\section{LOS TRABAJOS ARQUEOLÓGICOS EN LA CANTERA DE CORTIJO CEVICO}

El yacimiento se reconoció gracias a la dispersión de numerosos desechos de talla, percutores y restos de cantería en superficie. Para caracterizarlo se hizo una prospección intensiva mediante transectos de 1 x $50 \mathrm{~m}$ sobre toda la superficie.

Además, se excavaron dos sondeos: uno en la parte inferior y otro en la superior (Fig. 6.1) cuyos objetivos fueron la delimitación de la cantera, la definición de la secuencia estratigráfica, la determinación de los sistemas de extracción de la roca y su transformación.

\subsection{La prospección}

Se han catalogado un total de 396 piezas en la prospección de las cuales 335 son preformas, 35 lascas, 18 percutores y 8 piezas de sílex. 


\begin{tabular}{|c|c|c|c|c|c|c|}
\hline Yacimiento & Laboratorio & Tipo & Contexto & $\begin{array}{c}\text { Fecha } \\
\text { (BP) }\end{array}$ & $\begin{array}{l}\text { (95\% probabilidad } \\
\text { Cal AC) }\end{array}$ & Referencia \\
\hline $\begin{array}{l}\text { Cueva de los Mármoles } \\
\text { (Priego de Córdoba) }\end{array}$ & Beta-313471 & Cereal & UE-20 & $6250 \pm 40$ & $5316-5201$ & $\begin{array}{l}\text { (Peña-Chocarro } \\
\text { et al. 2013) }\end{array}$ \\
\hline $\begin{array}{l}\text { Cueva de los Mármoles } \\
\text { (Priego de Córdoba) }\end{array}$ & WK-25171 & Cereal & $\begin{array}{l}\text { "Silo" } \\
\text { Este }\end{array}$ & $6198 \pm 31$ & $5230-5048$ & $\begin{array}{l}\text { (Peña-Chocarro } \\
\text { et al. 2013) }\end{array}$ \\
\hline $\begin{array}{l}\text { Cueva de los Mármoles } \\
\text { (Priego de Córdoba) }\end{array}$ & Beta-313473 & Cereal & UE-40 & $6180 \pm 30$ & $5230-5049$ & $\begin{array}{l}\text { (Peña-Chocarro } \\
\text { et al. 2013) }\end{array}$ \\
\hline $\begin{array}{l}\text { Cueva de los Mármoles } \\
\text { (Priego de Córdoba) }\end{array}$ & Beta-313472 & Cereal & UE-30 & $6180 \pm 40$ & $5295-5041$ & $\begin{array}{l}\text { (Peña-Chocarro } \\
\text { et al. 2013) }\end{array}$ \\
\hline $\begin{array}{l}\text { Cueva de los Mármoles } \\
\text { (Priego de Córdoba) }\end{array}$ & Beta-313470 & Cereal & "Cabaña" & $6100 \pm 40$ & $5209-4932$ & $\begin{array}{l}\text { (Peña-Chocarro } \\
\text { et al. 2013) }\end{array}$ \\
\hline $\begin{array}{l}\text { Cerro Virtud (Cuevas de } \\
\text { Almanzora, Almería) }\end{array}$ & Beta-101424 & Carbón & Fase I & $6160 \pm 80$ & $5307-4909$ & $\begin{array}{c}\text { (Ruíz y Montero } \\
\text { 1999) }\end{array}$ \\
\hline $\begin{array}{l}\text { Cerro Virtud (Cuevas de } \\
\text { Almanzora, Almería) }\end{array}$ & Beta-90885 & Carbón & ¿Fase I? & $5920 \pm 70$ & $5058-4536$ & $\begin{array}{c}\text { (Montero y Ruíz } \\
1996)\end{array}$ \\
\hline $\begin{array}{l}\text { Cabecicos Negros } \\
\text { (Vera, Almería) }\end{array}$ & Beta-347627 & Concha & Fase I & $6530 \pm 30$ & $5619-5466$ & $\begin{array}{l}\text { (Camalich y } \\
\text { Martín 2013) }\end{array}$ \\
\hline $\begin{array}{l}\text { Cabecicos Negros } \\
\text { (Vera, Almería) }\end{array}$ & Beta-336255 & Concha & Fase I & $6470 \pm 30$ & $5543-5342$ & $\begin{array}{l}\text { (Camalich y } \\
\text { Martín 2013) }\end{array}$ \\
\hline $\begin{array}{l}\text { Cabecicos Negros } \\
\text { (Vera, Almería) }\end{array}$ & Beta-336258 & Concha & Fase I & $6340 \pm 30$ & $5470-5287$ & $\begin{array}{l}\text { (Camalich y } \\
\text { Martín 2013) }\end{array}$ \\
\hline $\begin{array}{c}\text { Los Castillejos } \\
\text { (Montefrío, Granada) }\end{array}$ & $\mathrm{Ua} 36215$ & Cereal & Fase 1 & $6310 \pm 45$ & $5380-5209$ & $\begin{array}{c}\text { (Cámara Serrano } \\
\text { et al. 2016) }\end{array}$ \\
\hline $\begin{array}{c}\text { Los Castillejos } \\
\text { (Montefrío, Granada) }\end{array}$ & $\mathrm{Ua} 36213$ & Cereal & Fase 2 & $6120 \pm 40$ & $5209-4953$ & $\begin{array}{c}\text { (Cámara Serrano } \\
\text { et al. 2016) }\end{array}$ \\
\hline $\begin{array}{c}\text { Los Castillejos } \\
\text { (Montefrío, Granada) }\end{array}$ & $\mathrm{Ua} 36214$ & Cereal & Fase 3 & $6260 \pm 45$ & $5323-5201$ & $\begin{array}{c}\text { (Cámara Serrano } \\
\text { et al. 2016) }\end{array}$ \\
\hline $\begin{array}{c}\text { Los Castillejos } \\
\text { (Montefrío, Granada) }\end{array}$ & B135663 & Cereal & Fase 3 & $6120 \pm 40$ & $5209-4953$ & $\begin{array}{c}\text { (Cámara Serrano } \\
\text { et al. 2016) }\end{array}$ \\
\hline $\begin{array}{c}\text { Los Castillejos } \\
\text { (Montefrío, Granada) }\end{array}$ & Ua36211 & Cereal & Fase 5 & $5400 \pm 45$ & $4345-4223$ & $\begin{array}{c}\text { (Cámara Serrano } \\
\text { et al. 2016) }\end{array}$ \\
\hline $\begin{array}{c}\text { Los Castillejos } \\
\text { (Montefrío, Granada) }\end{array}$ & Ua36212 & Cereal & Fase 6 & $6240 \pm 45$ & 5314-5194 & $\begin{array}{c}\text { (Cámara Serrano } \\
\text { et al. 2016) }\end{array}$ \\
\hline $\begin{array}{c}\text { Los Castillejos } \\
\text { (Montefrío, Granada) }\end{array}$ & B145302 & Cereal & Fase 7 & $6250 \pm 80$ & $5379-4997$ & $\begin{array}{c}\text { (Cámara Serrano } \\
\text { et al. 2016) }\end{array}$ \\
\hline $\begin{array}{c}\text { Los Castillejos } \\
\text { (Montefrío, Granada) }\end{array}$ & Ua36210 & Cereal & Fase 7 & $6100 \pm 45$ & $5209-4930$ & $\begin{array}{c}\text { (Cámara Serrano } \\
\text { et al. 2016) }\end{array}$ \\
\hline $\begin{array}{c}\text { Los Castillejos } \\
\text { (Montefrío, Granada) }\end{array}$ & Ua36209 & Cereal & Fase 9 & $6090 \pm 40$ & $5082-4900$ & $\begin{array}{c}\text { (Cámara Serrano } \\
\text { et al. 2016) }\end{array}$ \\
\hline $\begin{array}{c}\text { Los Castillejos } \\
\text { (Montefrío, Granada) }\end{array}$ & Ua36208 & Cereal & Fase $10 \mathrm{a}$ & $6120 \pm 40$ & $5209-4953$ & $\begin{array}{c}\text { (Cámara Serrano } \\
\text { et al. 2016) }\end{array}$ \\
\hline $\begin{array}{c}\text { Los Castillejos } \\
\text { (Montefrío, Granada) }\end{array}$ & Ua36203 & Cereal & Fase $11 b$ & $6115 \pm 40$ & $5208-4946$ & $\begin{array}{c}\text { (Cámara Serrano } \\
\text { et al. 2016) }\end{array}$ \\
\hline
\end{tabular}

Tab. 1 [1]. Dataciones absolutas de unidades estratigráficas procedentes de yacimientos arqueológicos con brazaletes en proceso de elaboración localizados en el sureste de la Península Ibérica. Las dataciones se han calibrado usando la curva atmosférica internacional IntCal13 (Reimer et al. 2013), y el programa de calibración OxCal v4.3.2 (Bronk Ramsey 2001). 


\begin{tabular}{|c|c|c|c|c|c|c|}
\hline Yacimiento & Laboratorio & Tipo & Contexto & $\begin{array}{c}\text { Fecha } \\
\text { (BP) }\end{array}$ & $\begin{array}{c}\text { (95\% probabilidad } \\
\text { Cal AC) }\end{array}$ & Referencia \\
\hline $\begin{array}{l}\text { Cueva de Los Murciélagos } \\
\text { (Zuheros, Córdoba) }\end{array}$ & OxA-15648 & Cereal & Fase A/41 & $6199 \pm 36$ & $5232-5047$ & $\begin{array}{c}\text { (Carvalho } \\
\text { et al. 2012) }\end{array}$ \\
\hline $\begin{array}{l}\text { Cueva de Los Murciélagos } \\
\text { (Zuheros, Córdoba) }\end{array}$ & OxA-15647 & Cereal & Fase A/45 & $6192 \pm 35$ & $5230-5035$ & $\begin{array}{c}\text { (Carvalho } \\
\text { et al. 2012) }\end{array}$ \\
\hline $\begin{array}{l}\text { Cueva de Los Murciélagos } \\
\text { (Zuheros, Córdoba) }\end{array}$ & GrN-6169 & Cereal & Nivel IV & $6150 \pm 45$ & $5220-4978$ & $\begin{array}{c}\text { (Vicent y Muñoz } \\
1973 \text { ) }\end{array}$ \\
\hline $\begin{array}{l}\text { Cueva de Los Murciélagos } \\
\text { (Zuheros, Córdoba) }\end{array}$ & OxA-15646 & Cereal & Fase A/66 & $6056 \pm 35$ & $5049-4847$ & $\begin{array}{l}\text { (Carvalho } \\
\text { et al. 2012) }\end{array}$ \\
\hline $\begin{array}{l}\text { Cueva de Los Murciélagos } \\
\text { (Zuheros, Córdoba) }\end{array}$ & OxA-15649 & Cereal & Fase $\mathrm{C} / 38$ & $6056 \pm 35$ & $5049-4847$ & $\begin{array}{l}\text { (Carvalho } \\
\text { et al. 2012) }\end{array}$ \\
\hline $\begin{array}{l}\text { Cueva de Los Murciélagos } \\
\text { (Zuheros, Córdoba) }\end{array}$ & GrN-6669B & Cereal & Nivel IV & $6025 \pm 45$ & $5016-4829$ & $\begin{array}{c}\text { (Pellicer y Acosta } \\
\text { 1997) }\end{array}$ \\
\hline $\begin{array}{c}\text { Cueva de Los Murciélagos } \\
\text { (Zuheros, Córdoba) }\end{array}$ & GrN-6669 & Cereal & Nivel IV & $6025 \pm 45$ & $5033-4799$ & $\begin{array}{c}\text { (Vicent y Muñoz } \\
1973)\end{array}$ \\
\hline $\begin{array}{l}\text { Cueva de Los Murciélagos } \\
\text { (Zuheros, Córdoba) }\end{array}$ & Beta-313477 & Cereal & Fase A/41 & $6140 \pm 40$ & $5215-4981$ & $\begin{array}{l}\text { (Peña-Chocarro } \\
\text { et al. 2013) }\end{array}$ \\
\hline $\begin{array}{l}\text { Cueva de Los Murcielagos } \\
\text { (Zuheros, Córdoba) }\end{array}$ & Beta-313476 & Cereal & Fase $\mathrm{C} / 27$ & $6110 \pm 40$ & $5208-4942$ & $\begin{array}{l}\text { (Peña-Chocarro } \\
\text { et al. 2013) }\end{array}$ \\
\hline $\begin{array}{l}\text { Cueva de Los Murciélagos } \\
\text { (Zuheros, Córdoba) }\end{array}$ & GrN-6638 & Carbón & Nivel V & $6025 \pm 45$ & $5033-4799$ & $\begin{array}{c}\text { (Vicent y Muñoz } \\
1973)\end{array}$ \\
\hline $\begin{array}{l}\text { Cueva de Los Murciélagos } \\
\text { (Zuheros, Córdoba) }\end{array}$ & GrN-6926 & Cereal & Nivel V & $6295 \pm 45$ & $5374-5206$ & $\begin{array}{c}\text { (Pellicer y Acosta } \\
\text { 1997) }\end{array}$ \\
\hline $\begin{array}{l}\text { Cueva de Los Murciélagos } \\
\text { (Zuheros, Córdoba) }\end{array}$ & Beta-316509 & Cereal & Fase $\mathrm{A} / 80$ & $6200 \pm 40$ & $5295-5045$ & $\begin{array}{l}\text { (Peña-Chocarro } \\
\text { et al. 2013) }\end{array}$ \\
\hline $\begin{array}{l}\text { Cueva de Los Murciélagos } \\
\text { (Zuheros, Córdoba) }\end{array}$ & Оха-15650 & Cereal & Silo 1969 & $6170 \pm 37$ & $5219-5010$ & $\begin{array}{l}\text { (Peña-Chocarro } \\
\text { et al. 2013) }\end{array}$ \\
\hline $\begin{array}{c}\text { Cueva de Los Murciélagos } \\
\text { (Zuheros, Córdoba) }\end{array}$ & Beta-313475 & Cereal & Fase $\mathrm{C} / 28$ & $5920 \pm 40$ & $4857-4709$ & $\begin{array}{l}\text { (Peña-Chocarro } \\
\text { et al. 2013) }\end{array}$ \\
\hline $\begin{array}{c}\text { Cueva de Los Murciélagos } \\
\text { (Zuheros, Córdoba) }\end{array}$ & GrN-6639 & Cereal & Nivel IV & $6025 \pm 45$ & $5206-4726$ & $\begin{array}{c}\text { (Vicent y Muñoz } \\
1973\end{array}$ \\
\hline $\begin{array}{c}\text { Abrigos del Pozo } \\
\text { (Calasparra, Murcia) }\end{array}$ & I-16783 & Carbón & Nivel VI & $6260 \pm 120$ & $5476-4941$ & (Martínez 1994) \\
\hline
\end{tabular}

Tab. 1 [2]. Dataciones absolutas de unidades estratigráficas procedentes de yacimientos arqueológicos con brazaletes en proceso de elaboración localizados en el sureste de la Península Ibérica. Las dataciones se han calibrado usando la curva atmosférica internacional IntCal13 (Reimer et al. 2013), y el programa de calibración OxCal v4.3.2 (Bronk Ramsey 2001).

La prospección nos ha permitido definir la concentración de materiales en una superficie de unos $2000 \mathrm{~m}^{2}$. La distribución es relativamente homogénea en la ladera que ocupa el afloramiento, aunque es más densa en la parte inferior (Fig. 6:1). Los únicos bloques de dolomía expuestos a la intemperie y agarrados al sustrato geológico, se hallan en la parte superior del afloramiento. Carecen de materiales arqueológicos asociados, aunque sí hemos documentado la extracción de pedazos de estos bloques.

Un estudio de pendientes ha valorado la posible erosión y transporte de los materiales en ladera. Se han cartografiado las zonas de acumulación de pendientes representadas por los tonos más claros (Fig. 6:2) y, además, la concentración de materiales arqueológicos (Fig. 6:3). La superposición de ambos mapas nos ha permitido definir las zonas donde la aglomeración del material es debida a procesos de erosión, transporte y sedimentación geológica por gravedad (Fig. 6:2, 3, elipses con línea continua). Pero también se observan aglutinaciones de materiales sin relación con las pendientes y que deben interpretarse como de origen antrópico (Fig. 6:2, 3 elipses con línea discontinua). 

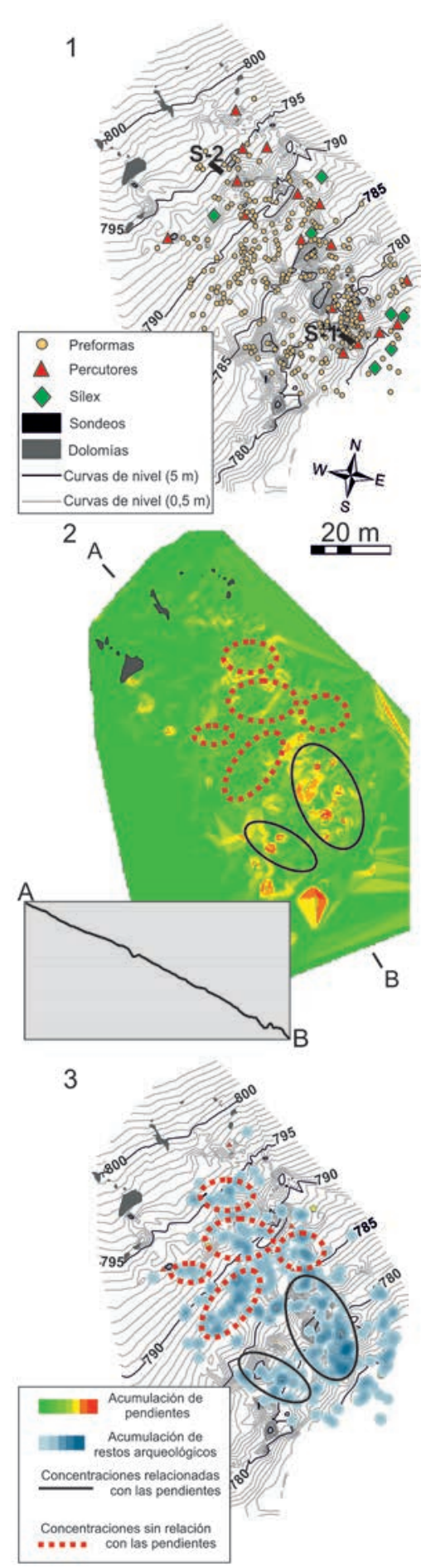

Fig. 6. Topografía de la cantera de Cortijo Cevico. 1. Distribución de materiales arqueológicos y situación de los sondeos S-1 y S-2 (modificado a partir de Martínez-Sevilla et al. 2016); 2. Concentración de pendientes y su corte A-B; 3 . Acumulación de materiales arqueológicos y su relación con las pendientes. La base cartográfica es de elaboración propia (en color en la edición electrónica).

\subsection{Los sondeos}

El sondeo 1 (S-1, 4 x $1 \mathrm{~m})$ se situó cerca del camino que corta el yacimiento en su cota inferior y orientado de sur a norte (Fig. 7A). La situación de S-1 junto con la concentración de las pendientes y los materiales arqueológicos indicaron una sedimentación geológica de ladera en esta zona del afloramiento. En la excavación del sondeo se identificó una única unidad sedimentaria
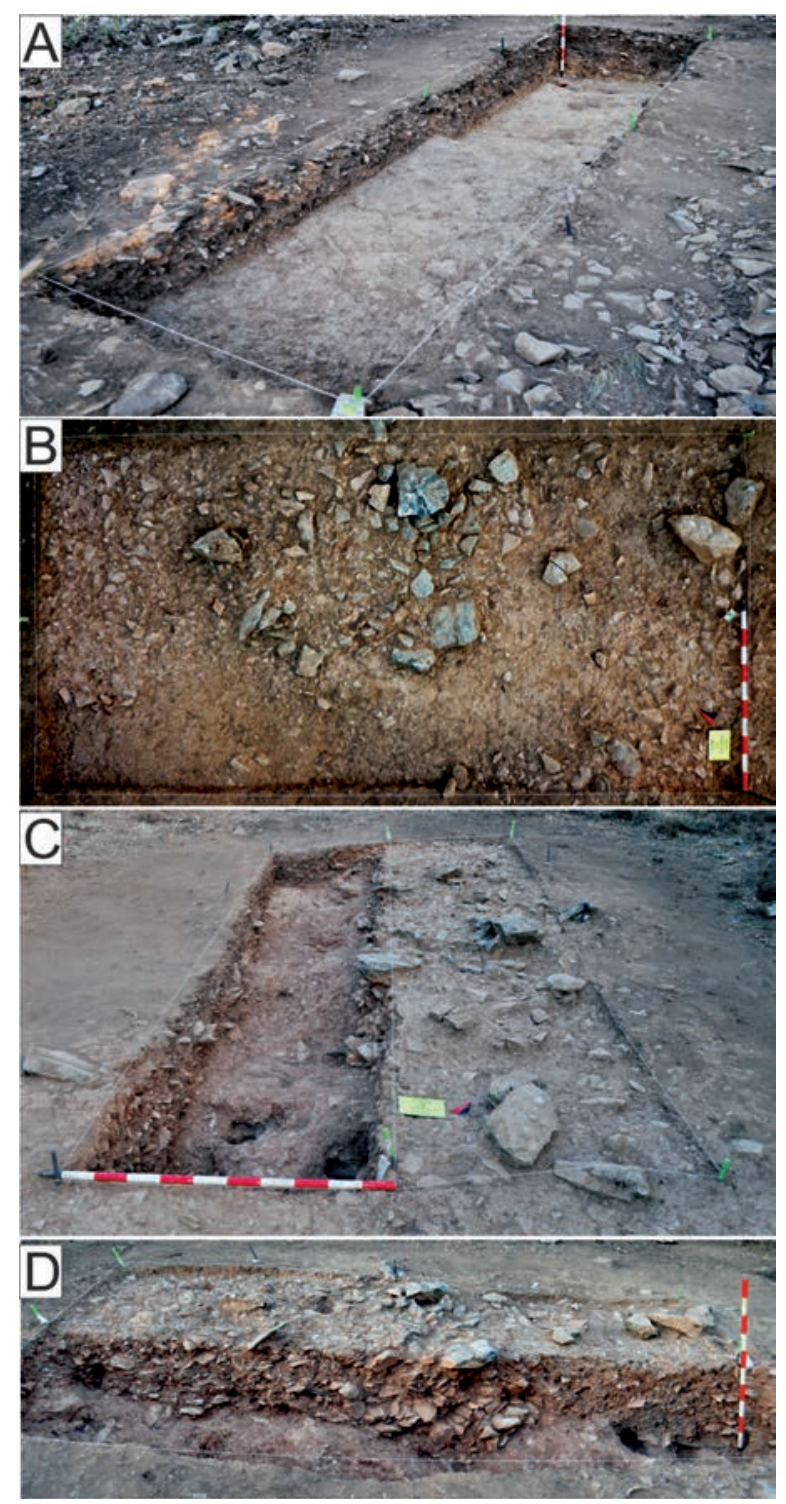

Fig. 7. Sondeos realizados en la cantera de Cortijo Cevico: A. Vista general del Sondeo 1 desde el noroeste; B. Fotografía cenital del Sondeo 2 una vez retirada la capa de sedimentos superficiales; C. Vista desde el este del Sondeo 2 una vez rebajados los cuadrantes sur hasta la base geológica; D. Perfil central del Sondeo 2 desde el sur (en color en la edición electrónica). 
de origen erosivo (UE 01). Este sondeo solo nos ha permitido documentar los procesos de erosión, transporte y depósito de ladera en la zona baja del yacimiento.

El sondeo $2(\mathrm{~S}-2,2$ × $4 \mathrm{~m})$ se situó en la parte alta del afloramiento, coincidiendo el eje máximo con la ladera y con una zona donde la pendiente no es tan acusada. El sondeo se hizo coincidir con un conjunto de bloques tallados y algunas preformas que sobresalían de la capa edáfica. Tras la retirada de esta capa edáfica de unos $5 \mathrm{~cm}$ (UE 00) se puso al descubierto una unidad arqueológica totalmente cubierta de desechos de talla y bloques de mediano tamaño, y se definieron las dos unidades estratigráficas UE 01 y UE 02 (Fig. 7B). La excavación se centró en los cuadrantes de la parte sur para conocer la relación de las UEs y documentar la sedimentación de la parte central del sondeo (Fig. 7C). Así, se retiró la UE 02 en contacto con la UE 01 que apoyaba sobre la base geológica (UE 03). Definiéndose la UE 01 como un lentejón decreciente hacia la zona sur. Una vez definida, la UE 01 se retiró en las cuadrículas de la zona sur hasta la base geológica (UE 03), formada por arcillas, yesos y margas con clastos de calizas y bloques

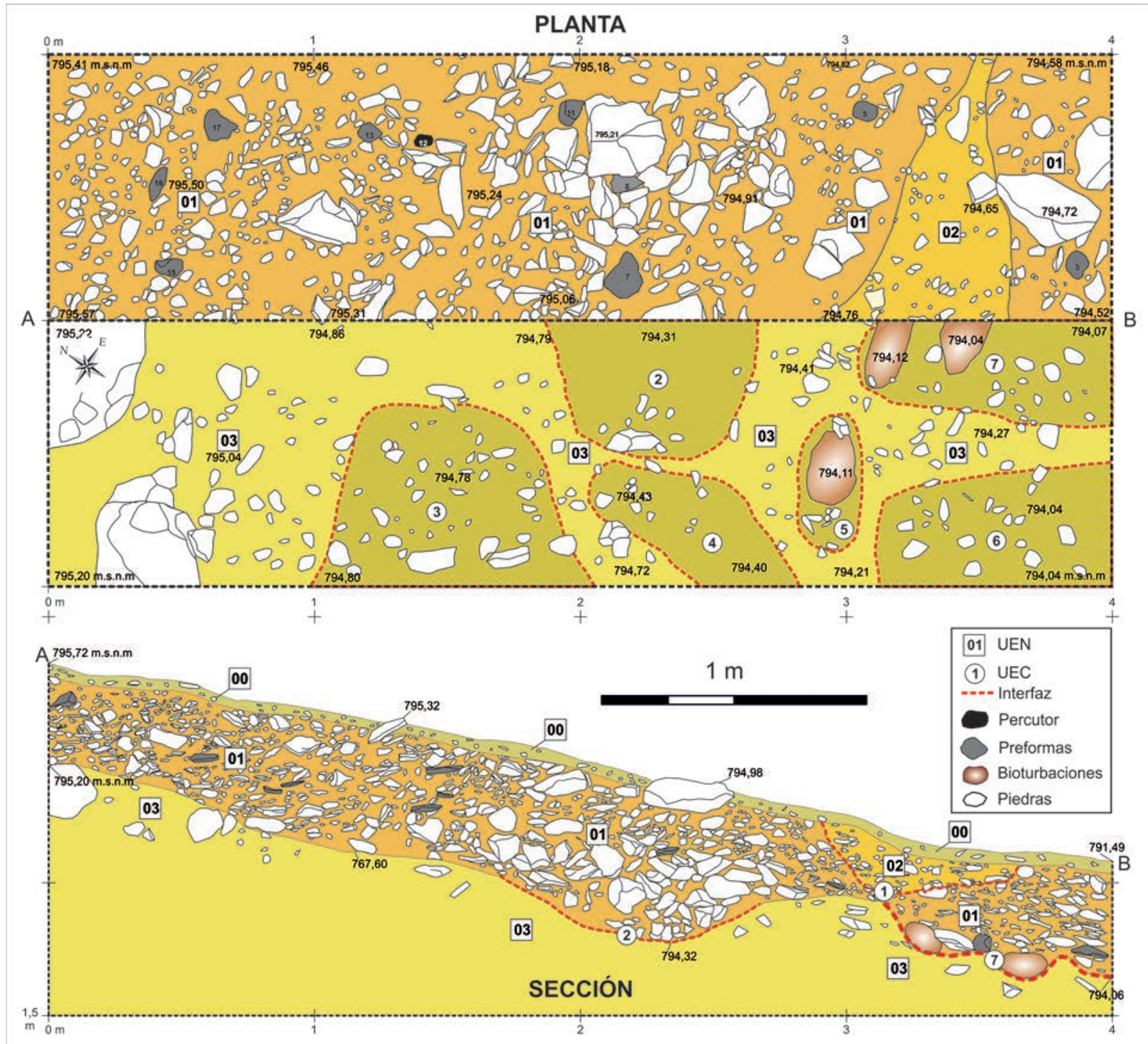

Fig. 8. Planta y sección del Sondeo 2 de la cantera de Cortijo Cevico, con la distribución de materiales arqueológicos. Obsérvense los procesos antrópicos relacionados con las bioturbaciones y las interfaces de las unidades estratigráficas construidas (UEC) y las unidades estratigráficas naturales que las rellenan (UEN) (en color en la edición electrónica). 
de mármol. La UE 01 se componía de una matriz suelta con bloques de mediano tamaño la mayoría con golpes, restos de talla y preformas. Como se observa en el perfil noroeste, los bloques se disponen sin orientación alguna ni selección de tamaños por procesos gravitacionales (Fig. 7D). Se trata de un estrato antrópico creado por la excavación del sustrato. El relleno de las 6 unidades estratigráficas excavadas en la base geológica era menos compacto, de ahí que hubiera madrigueras en los contactos entre la base geológica inalterada y el estrato antrópico inmediatamente superior (Fig. 8).

En el S-2 no se constataron procesos erosivos. Las unidades estratigráficas UE 01 y UE 02 son dos momentos de la excavación en el sustrato geológico para la extracción del mármol y fruto de las acumulaciones de sedimento y detritus de la talla. La UE 01 se corresponde con el primer momento y se asienta sobre las estructuras horadadas sobre él. Consiste en bloques probados con uno o dos golpes para valorar la calidad y desechados en unos casos o tallados en otros como preformas. La UE 02 corta y se apoya en algunas partes del sondeo en la UE 01. Este sondeo ha permitido identificar el sistema de extracción de los bloques de la matriz geológica e interpretar estas actividades en varios momentos, generando lentejones de restos de talla y detritus que se superponen o se cortan entre ellos.

\subsection{Los restos materiales de la cantera}

\subsubsection{Desechos de extracción y transformación}

Los bloques tallados de mayor tamaño se pueden considerar núcleos para la extracción de grandes lascas a partir de las cuales se tallan las preformas. Estos bloques aparecen por toda la superficie del yacimiento (Fig. 9C). Las técnicas de talla empleadas debieron ser la percusión lanzada, la explotación centrípeta en ambas caras del bloque (Fig. 9B) y la extracción mediante un frente único (Fig. 9A). Los bloques de mediano tamaño con golpes para probar la calidad de la roca, se documentan en la superficie del afloramiento, pero sobre todo en las unidades sedimentarias en relación directa con los hoyos de extracción.

Las grandes lascas son uno de los soportes a partir de los cuales se tallan las preformas. Son lascas extraídas con percusión lanzada de los bloques antes descritos (Fig. 9H). Las dimensiones de las lascas varían entre 10 y $15 \mathrm{~cm}$ de longitud, 10 y $20 \mathrm{~cm}$ de anchura y 4 y $6 \mathrm{~cm}$ de grosor. Los estigmas de talla son bulbos o pseudobulbos marcados, aunque en muchos casos son imperceptibles por el tipo de fractura en split. Los accidentes de fractura tipo Siret son frecuentes por el tipo de percusión violenta y perpendicular.
Los desechos de desbastado, por lo general, no poseen una morfología determinada ni estigmas técnicos de talla. Son los restos generados en el proceso de extracción de las grandes lascas de transformación de los bloques naturales.

En los desechos de talla el elemento más característico son las lascas, producto del tallado de las preformas clasificadas en dos tipos. Las lascas de percusión (Fig. 10E, F), con bulbos marcados generalmente más anchas que largas de 3 a $6 \mathrm{~cm}$ y entre 50 a $100 \mathrm{~mm}$ de grosor. En las lascas de preforma (Fig. 10G) se observa la curvatura circular y no se aprecian bulbos u otro tipo de estigmas de la talla. También se han documentado lascas de ofita y sílex provenientes de accidentes en los trabajos de percusión con los percutores.

\subsubsection{Los productos y los útiles}

Las preformas son los productos que se tallan en la cantera, de ahí que sean el grupo más numeroso con 442 piezas y el que más información permite extraer sobre las técnicas y métodos de talla. En el yacimiento

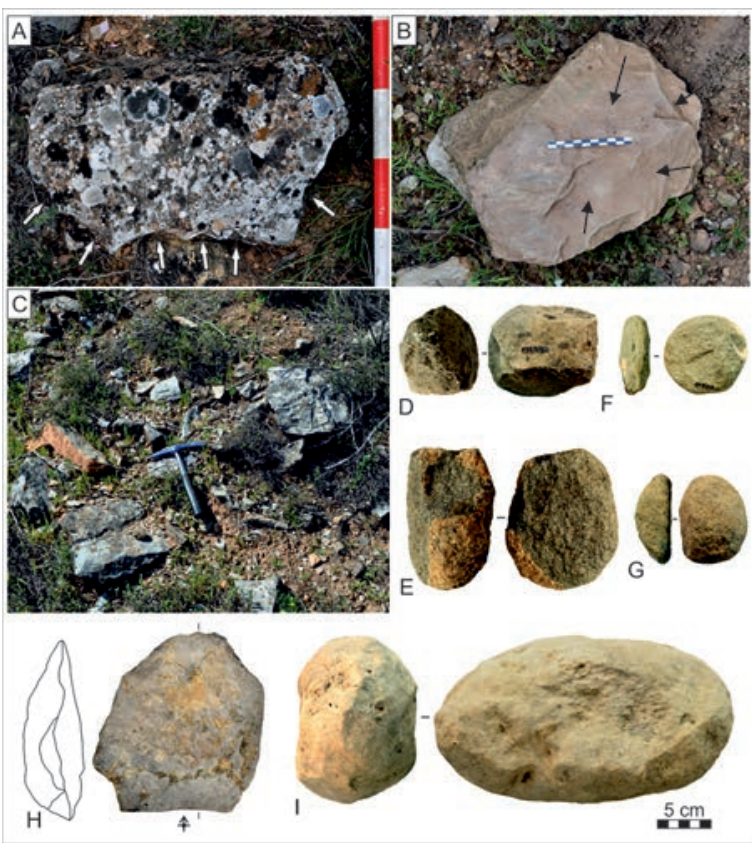

Fig. 9. Materiales arqueológicos de la cantera de Cortijo Cevico. Bloques de mármol: A. con explotación frontal de grandes lascas, B. con extracciones centrípetas de grandes lascas; C. Superficie de la cantera con bloques, grandes lascas y restos de desbastado. Percutores: D. de tipo medio de mármol (973 g), E. de tipo medio de ofita $(1067 \mathrm{~g}), \mathrm{F}$ - G. de pequeño tamaño de ofita $(350 \mathrm{~g})$. H. Gran lasca de mármol. I. Percutor de grandes dimensiones de caliza $(5500 \mathrm{~g})$ (modificado a partir de Martínez-Sevilla et al. 2016) (en color en la edición electrónica). 
están las que se abandonaron sin usar en el proceso de trasformación. Se han clasificación según la fractura de la preforma o la causa del abandono en los tipos: medial (Fig. 10D) con una rotura en la parte central; fractura longitudinal (Fig. 10B) debida a un plano de foliación del mármol; medial-longitudinal, que combina los dos tipos anteriores; lascado sobrepasado (Fig. 10C), levantamiento que hace inviable su transformación. Finalmente, las preformas inviables (Fig. 10A) incluyen todas las que ni poseen los atributos antes descritos ni aparentemente defectos que forzaran su desechado.

Los 23 percutores son los únicos útiles identificados en la cantera. Las litologías corresponden a ofitas y al propio mármol existente en la cantera, en los mismos porcentajes, y solo uno al sílex. Al tratarse de elementos destinados a la percusión se clasifican según su peso en tres grupos: el de gran tamaño con un solo ejemplar de 5500 g (Fig. 9I); el de mediano

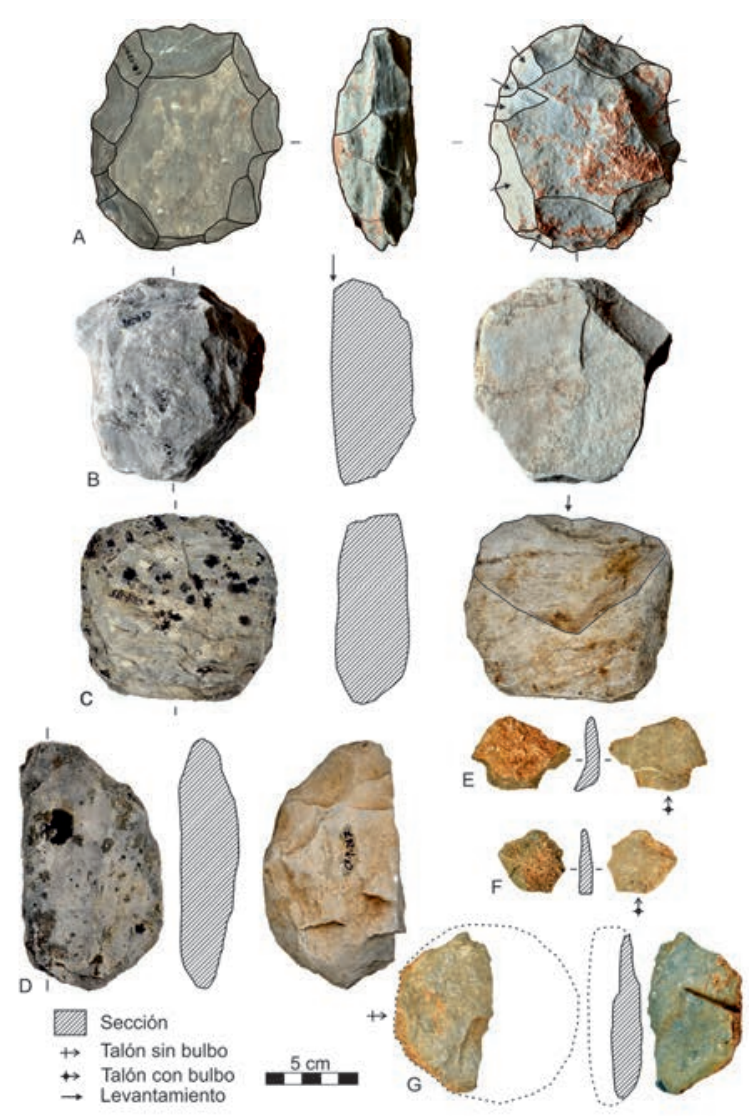

Fig. 10. Materiales arqueológicos de la cantera de Cortijo Cevico. Preformas: A. abandonada por inviabilidad tallada bifacialmente, B. con fractura longitudinal, C. con levantamiento sobrepasado, D. con fractura medial. Lascas: E-F. de conformación, G. de preforma (en color en la edición electrónica). tamaño comprende los que pesan entre 1000 y $2000 \mathrm{~g}$ (Fig. 9D, E) y el de pequeño tamaño, los más comunes de hasta 1000 g (Fig. 9F, G). Los percutores de ofita debieron ser aportados de los afloramientos geológicos cercanos y su forma redondeada es debida a las actividades de percusión. En el "Trías de Antequera" no hay cantos rodados de estas rocas, pues el transporte desde las fuentes naturales hasta los arroyos o ríos no es suficiente para redondear estas litologías tan duras. En algunos afloramientos, sobre todo en las partes más externas de las inclusiones magmáticas, estas suelen meteorizar en "cáscara de cebolla" ofreciendo formas redondeadas, pero fácilmente distinguibles de los ejemplos documentados en la cantera.

\section{EXTRACCIÓN DE LA MATERIA PRIMA Y TÉCNICAS DE TRANSFORMACIÓN}

En un primer momento de uso de la cantera, se pudo utilizar el laboreo superficial de bloques que afloraran por diversos procesos tectónicos o erosivos. En los bloques que aparecen en su contexto geológico primario, hemos documentado algunas zonas de extracción, pero no desechos de talla (Fig. 6: 1), por lo que podría indicar el soterramiento de estos bloques y su aprovechamiento mínimo.

La mélange de margas, arcillas y yesos contienen los bloques de mármol por lo que la extracción más común es la excavación en el sustrato geológico para acceder a la materia prima. Son excavaciones a cielo abierto poco profundas, ya que la matriz geológica debió aflorar cerca de la cobertura vegetal. Las horadaciones tienen entre 50 y $60 \mathrm{~cm}$ de profundidad y probablemente se correspondan con bloques de mármol dolomítico arrancados de la base geológica. No hemos identificado ningún tipo de utensilio relacionable con la actividad de excavación. Por analogía, con otros contextos mineros de sílex neolíticos, debieron emplearse astas de ciervo o simples palos cavadores, dada la poca profundidad y el tipo de sedimento (Holgate 1995: 152; Capote 2013: 376; Castañeda 2014: 34). Las acumulaciones de bloques testados, preformas y desechos de talla, en relación directa con los lugares de extracción, indican la sincronía entre la elaboración de las preformas y el proceso de extracción. Esta sincronía está documentada igualmente en minas de sílex (Capote 2011; Castañeda 2014: 27). Los lentejones entrecortados de sedimento con restos de extracción y talla corresponden a diferentes momentos de excavación en la cantera.

Las preformas se han obtenido a partir de dos tipos de soportes: bloques o tabletas de mármol en su estado natural y grandes lascas (Martínez-Sevilla et al. 2016). La procedencia del soporte ha podido ser determinada 
en un $42 \%$ de las preformas, predominando el uso de grandes lascas $(40 \%)$, frente a los soportes geológicos naturales $(16 \%)$.

Relacionamos la extracción de las grandes lascas con los grandes bloques tallados mediante percusión lanzada (Fig. 9A, B, C), con el gran percutor cuyo peso es de más de cinco kilogramos (Fig. 9I). Este procedimiento ha sido documentado para la elaboración de hachas pulimentadas en ofita en el cercano afloramiento de Cortijo Martilla (Morgado et al. 2013). Al ser el mármol un material mucho más blando y por tanto de extracción más sencilla, también pudo utilizarse la percusión directa con percutores entre 1 y $2 \mathrm{~kg}$.

\subsection{Técnicas y métodos de talla}

El mármol dolomítico por sus características texturales posee una fractura casi concoidea, pero al haber sufrido en general un bajo grado de metamorfismo (Sanz de Galdeano et al. 2008), en algunas zonas presenta una foliación o planos de discontinuidad. La técnica de talla identificada ha sido la percusión directa con los percutores de menor tamaño y peso, de ahí que sean el conjunto más numeroso (18 piezas). Las preformas circulares resultantes son en forma de disco, con un diámetro y grosor determinados. La percusión se ejecuta oblicua $\left(45^{\circ}\right)$ o perpendicular $\left(90^{\circ}\right)$ al plano de percusión. La oblicua produce levantamientos que configuran la forma circular; y la perpendicular genera lascas que adelgazan el grosor. Las lascas de preforma, se pueden producir por un plano de fractura ya existente en el mármol e incluso llegar a producir una fractura longitudinal en la preforma.

La reconstrucción de los métodos de talla se ha basado en el estudio de las preformas abandonadas en un estado inicial de transformación. El análisis mediante esquemas diacríticos nos ha permitido definir la orientación de las series de talla y las secuencias de los levantamientos (Martínez-Sevilla et al. 2016). Se suelen usar dos series de levantamientos, cuyas direcciones pueden ser ascendente y descendente, o dos ascendentes que convergen. La talla de estas series puede ser bifacial alterna en grupos de 1 a 5 golpes o unifacial. En algunas preformas se ha observado la talla sobre yunque.

En el transcurso de la talla se producen roturas y abandonos que son un efecto directo del tipo de técnica y materia prima empleada (Tab. 2). Si consideramos las características foliáceas de la roca, las fracturas longitudinales por plano de fractura deberían ser las más numerosas, pero suponen $8,3 \%$ del total de las preformas. Este bajo porcentaje viene determinado por la selección cuidadosa de una materia prima sin planos de fractura bien definidos y buena homogeneidad. El tipo de rotura más común en las piezas es la medial $(34,3 \%)$, debido al empleo de la percusión directa y violenta. Le siguen las inviables (31\%), cuyo porcentaje puede estar relacionado con el tipo de materia prima y con unas dimensiones inadecuadas de la misma. Durante la talla se pueden advertir impurezas o planos de fractura en la preforma y al no poder conformarla, con unas determinadas medidas, se abandona. Llama la atención las preformas que se siguen tallando aun cuando sus medidas y materia prima no sean las idóneas. Estas piezas inviables se pueden relacionar con procesos de aprendizaje en la cantera, como se ha referido para minas de sílex (Castañeda 2014: 342).

\begin{tabular}{|l|c|c|}
\hline \multicolumn{1}{|c|}{ Tipo de fractura o abandono } & N & Porcentaje \\
\hline Inviable & 138 & $29,4 \%$ \\
\hline Lascado sobrepasado & 70 & $14,9 \%$ \\
\hline Fractura longitudinal & 39 & $8,3 \%$ \\
\hline Fractura medial & 161 & $34,3 \%$ \\
\hline Fractura medial-longitudinal & 34 & $7,2 \%$ \\
\hline Total & 442 & $100 \%$ \\
\hline
\end{tabular}

Tab. 2. Tipo de preformas de la cantera de Cortijo Cevico.

\section{ESTANDARIZACIÓN DE LA PRODUCCIÓN Y TEMPORALIDAD DE LA CANTERA}

Los procesos de trabajo llevados a cabo en Cortijo Cevico están destinados a la elaboración de una forma muy concreta. El grado de estandarización de la producción se ha definido mediante el estudio comparativo y estadístico de las dimensiones y la morfología de las preformas. Para su caracterización se han comparado gráficamente el perfil de la sección y el perímetro exterior (Fig. 11). Para el perfil se han seleccionado 120 preformas sin fracturas longitudinales y para el perímetro otras sin fracturas mediales. La superposición de las líneas muestra que el perímetro exterior se ajusta a una morfología determinada (Fig. 11:1), pero la sección, aunque tiene cierta homogeneidad, no define una forma preestablecida (Fig. 11:2).

El análisis morfométrico indica una clara agrupación entre largo y ancho (Fig. 12) y otra entre largo y grosor pero este último con una distribución más amplia (Fig. 13).

La variabilidad de las medidas se ha calculado mediante el coeficiente de variación (CV) que relaciona el tamaño de la media y la variabilidad de la variable. Su fórmula expresa la desviación estándar como porcentaje de la media aritmética, mostrando una mejor interpretación porcentual del grado de variabilidad que la 


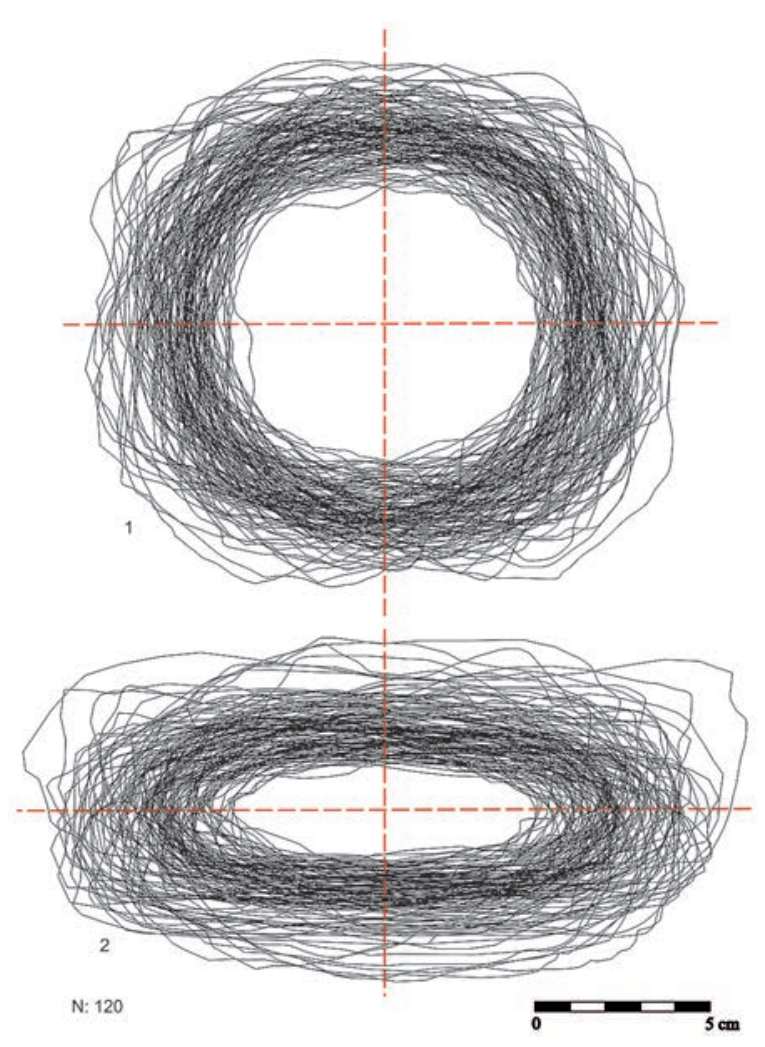

Fig. 11. Superposición de los contornos exteriores (1) y los perfiles de las secciones (2) de 120 preformas de la cantera de Cortijo Cevico.

desviación estándar. Así, a mayor valor del CV mayor heterogeneidad de la variable; y a menor CV, mayor homogeneidad en la variable. Los cálculos se han realizado mediante la fórmula:

$$
C_{V}=\frac{\sigma}{\bar{x}} \cdot 100
$$

Donde $\sigma$ es la desviación estándar y $\bar{x}$ es la media. Los cálculos realizados sobre las tres mediciones de las preformas sitúan el CV del largo y ancho en el $17 \%$ y el del grosor en el $39 \%$. En estadística existe homogeneidad en las variables siempre que el CV sea inferior al $20 \%$. En este caso, el largo y el ancho cumplen esta premisa, pero el grosor la sobrepasa (Tab. 3).
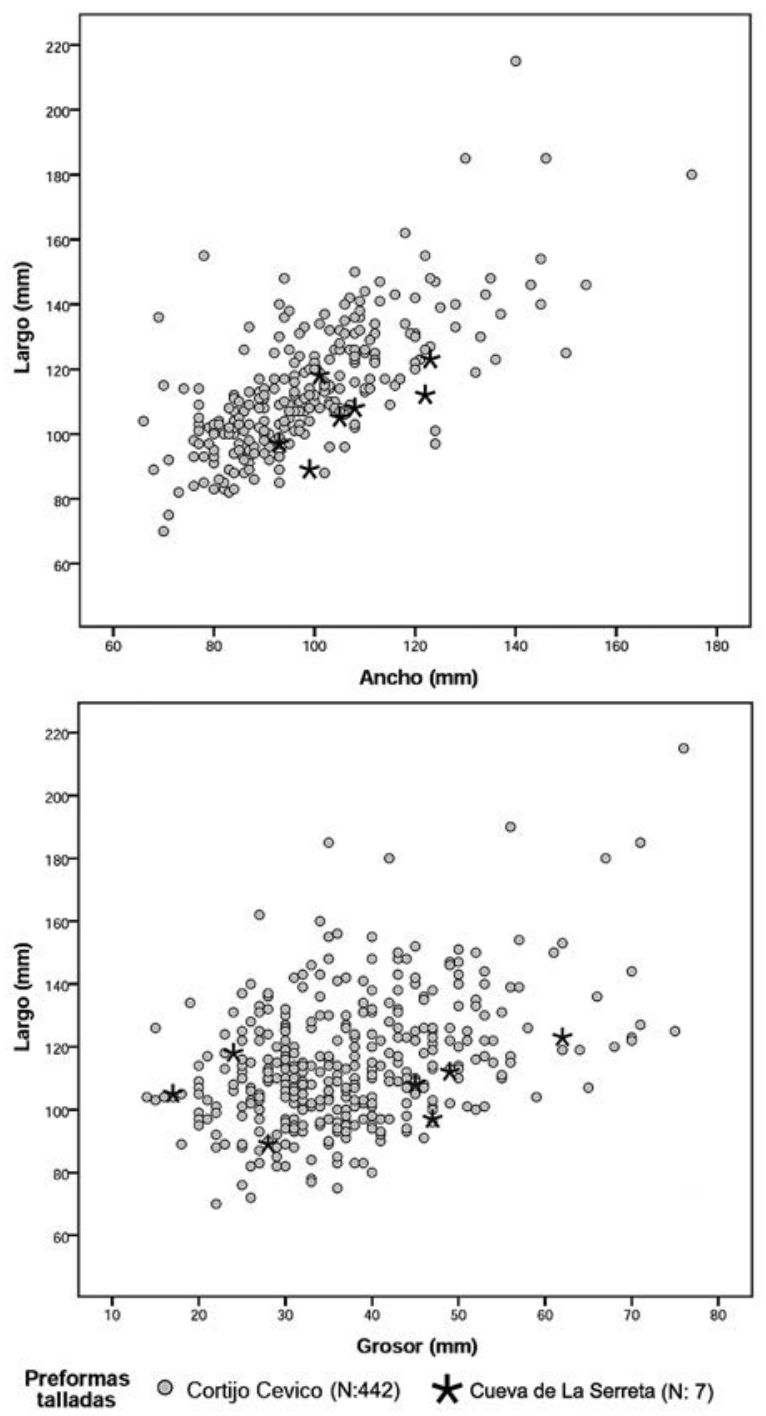

Fig. 12. Comparación de las preformas de la cantera de Cortijo Cevico con las del taller de brazaletes de la Cueva de La Serreta (Cieza, Murcia).

Podemos afirmar que está estandarizado el diámetro exterior que coincide con las variables largo y ancho. La estandarización es más evidente si consideramos que son elementos tallados y en una primera

\begin{tabular}{|c|c|c|c|c|c|c|}
\hline Medidas & $\mathbf{N}$ & Mínimo & Máximo & Media & Desviación Estándar & Coeficiente de variación \\
\hline Largo (mm) & 434 & 70 & 515 & 112,87 & 19,762 & $17,5 \%$ \\
\hline Ancho (mm) & 267 & 66 & 175 & 99,05 & 16,983 & $17,14 \%$ \\
\hline Grosor $(\mathbf{m m})$ & 382 & 14 & 76 & 37,34 & 11,109 & $39,75 \%$ \\
\hline
\end{tabular}

Tab. 3. Estadísticos descriptivos de las preformas de Cortijo Cevico. 


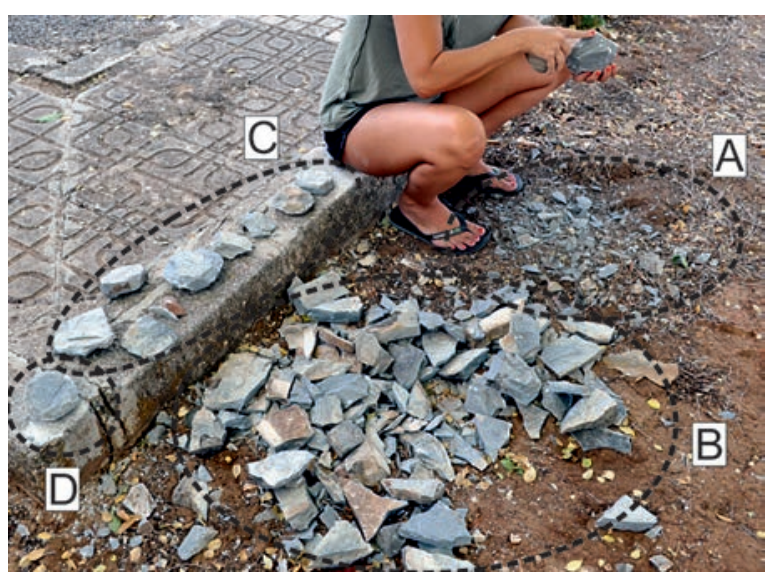

Fig. 13. Reproducción experimental de la elaboración de preformas llevada a cabo en la cantera de Cortijo Cevico: A. Lascas y debris de talla de las preformas, B. Restos del desbastado y extracción de grandes lascas, C. Preformas abandonadas por fracturas accidentales o inviabilidad, D. Preforma viable para elaborar un brazalete (en color en la edición electrónica).

fase de elaboración. Están destinados a la elaboración de brazaletes, cuyos diámetros externos fluctúan entre los 50 y los $130 \mathrm{~mm}$ (70 mm de media), según las piezas acabadas estudiadas (Martínez-Sevilla 2016: 446). No existe una estandarización tan marcada del grosor, ya que se pueden elaborar brazaletes con diferentes alturas. Agrupando las preformas cada $10 \mathrm{~mm}$ las más numerosas están entre 30-40 $\mathrm{mm}$ con parecida representación que las comprendidas entre $40-50 \mathrm{~mm}$ y 20-30 $\mathrm{mm}$. Según estas agrupaciones se producirían brazaletes del tipo estrecho, pero sobre todo del tipo medio y ancho. La comparación de las preformas de la cantera de Cortijo Cevico con las del taller de brazaletes de La Serreta (Martínez-Sevilla y Salmerón 2014), cuyo contexto cronocultural y de producción está bien definido, nos muestra que el tipo de piezas que se pudieron elaborar en la cantera son semejantes a las de ese taller. Comparten la distribución de las variables largo y ancho, así como largo y grosor (Fig. 12).

\subsection{Temporalidad de la cantera y tipo de aprovechamiento}

¿Cuánto tiempo se aprovechó el afloramiento? ¿Se trata de una explotación intensiva o esporádica? ¿Qué poblaciones extrajeron el mármol y produjeron las preformas? Quizás sean preguntas complicadas de responder con el registro arqueológico, pero caben algunas apreciaciones.

La observación del abundante registro material de este tipo de canteras quizá llevaría a sobredimensionar las actividades allí efectuadas. Las experimentaciones nos ofrecen una visión más real de la cantidad de desechos generados al elaborar las preformas. Las experimentaciones se han centrado en el comportamiento de la roca durante la talla y en la identificación de los estigmas técnicos y de los desechos generados en el proceso. La transformación de los bloques y el tallado de preformas en una hora de actividad generan una ingente cantidad de materiales de desecho y preformas abandonadas por su fractura o inviabilidad (Fig. 13). Si la comparamos con el registro arqueológico de la cantera, nuestra visión sobre la intensidad de la producción puede variar sensiblemente. La inclusión de la variable tiempo es fundamental al interpretar este tipo de contextos. Si atribuimos a la cantera un uso esporádico en ciertos momentos del año, distribuido durante un centenar de años, vemos un aprovechamiento muy local y nada intensivo.

El análisis de las materias primas de los elementos arqueológicos documentados sitúa las áreas de captación en el entorno más inmediato a Cortijo Cevico. Las poblaciones que aprovecharon la cantera debieron ser locales. Los afloramientos de ofitas empleadas como percutores distan escasos cientos de metros de la cantera, como los restos de sílex provenientes del cercano valle de los Gallumbares (Subbético medio). Además, como este tipo de mármol dolomítico no es una materia prima difícil de localizar en la formación geológica del "Trías de Antequera", parece improbable un desplazamiento de poblaciones en busca de un recurso relativamente abundante en la zona. Es posible que otros bloques de este tipo de roca o similar se aprovechasen, como el de Cortijo Cevico, a lo largo del "Trías de Antequera". Un ejemplo es la cantera del Cerro del Moro con escasos restos de brazaletes en elaboración cuya materia prima es de mejor calidad que la de Cortijo Cevico. Debió usarse de manera recurrente pero los desechos de cantería prehistóricos fueron destruidos por la explotación histórica. Este dato nos muestra que posiblemente el aprovechamiento de los mármoles dolomíticos de Cortijo Cevico fuera algo secundario que nos ha llegado gracias al desinterés industrial moderno. Desconocemos el o los motivos por los que se explotó esta cantera en concreto: cercanía a un asentamiento, colores llamativos, materia prima con características de talla adecuadas, etc.

\section{CONCLUSIONES}

Las evidencias cronológicas asociadas a la artesanía de los brazaletes y su uso como adornos permiten situar el aprovechamiento de la cantera de Cortijo Cevico en el Neolítico Antiguo (ca. 5500-4800 cal AC). El momento exacto de uso es imprecisable por la ausencia de restos orgánicos susceptibles de ser datados 
por métodos radiocarbónicos. En el afloramiento se extrajo materia prima mediante excavación en el sustrato geológico y se tallaron preformas circulares para la elaboración de brazaletes. Las técnicas y métodos de talla son muy homogéneos en todo el conjunto estudiado. La ordenación de los levantamientos, los puntos de percusión y la homogeneidad de las lascas muestra la destreza de los talladores. Sin embargo, también se aprecian características asociadas a procesos de aprendizaje como las preformas de reducidas dimensiones, talladas aun siendo inviables, la talla unifacial y sobre yunque.

El coeficiente de variación indica una estandarización en el diámetro de las preformas. En cambio, los grosores se agrupan en varios conjuntos relacionados con los tipos de brazaletes que se podrían elaborar, en general medios y anchos. El uso de la cantera debió ser esporádico, dilatado en el tiempo y a cargo de poblaciones del entorno más inmediato, por lo que no han quedado restos domésticos de ocupaciones. No consideramos que se trate de una explotación intensiva para una producción masiva, sino más bien un lugar frecuentado para obtener preformas que serán transformadas en brazaletes en los asentamientos. El afloramiento debió ser uno entre otros destinados a este fin en torno a esta área geográfica y geológica.

Concluyendo, hemos documentado y estudiado en Cortijo Cevico la explotación de la primera cantera de mármol conocida en la Península Ibérica cuyo único fin fue elaborar brazaletes durante el Neolítico Antiguo. Los resultados obtenidos en la prospección y excavación son pioneros para la comprensión de la cadena operativa de estos adornos tan paradigmáticos del Neolítico Antiguo del mediodía peninsular.

\section{BIBLIOGRAFÍA}

Bronk Ramsey, C. 2001: "Development of the radiocarbon calibration program". Radiocarbon 43(2): 355-63. https://doi.org/10.1017/s0033822200038212

Camalich Massieu, M. D. y Martín Socas, D. 2013: "Los inicios del Neolítico en Andalucía. Entre la tradición y la innovación". Menga 4: $103-132$.

Cámara Serrano, J. A.; Afonso, J. A. y Molina González, F. 2016: “La ocupación de las Peñas de los Gitanos (Montefrío, Granada) desde el Neolítico al mundo romano. Asentamiento y ritual funerario". En R. J. Pedregosa Mejías (ed.): Arqueología e Historia de un paisaje singular: la Peña de los Gitanos de Montefrio (Granada). Excm. Ayuntamiento de Montefrío. Jaén: 18-121.

Capote, M. 2013: Trabajo y comunidad en el Neolítico antiguo: los útiles de percusión de la mina de sílex de Casa Montero (Madrid). Tesis Doctoral. Universidad Complutense de Madrid. https://eprints.ucm.es/21868/ (consulta 03-08-2018).

Carrasco Rus, J.; Gámiz Jiménez, J.; Pachón Romero, J. A. y MartínezSevilla, F. 2011: "El poblamiento neolítico en el Subbético Interno del Poniente de Granada". Antiqvitas 23: 5-45.

Carrasco Rus, J. y Martínez-Sevilla, F. 2014: "Las cronologías absolutas del Neolítico Antiguo en el sur de la península ibérica. Nuevas dataciones". Archivo de Prehistoria Levantina XXX: 57-80.
Carrasco Rus, J.; Navarrete Enciso, M. S.; Pachón Romero, J. A.; Pastor Muñoz, M.; Gámiz Jiménez, J.; González, C. A. y Toro Moyano, I. 1986: El poblamiento antiguo en la tierra de Loja. Excmo. Ayuntamiento de Loja. Granada.

Carvalho, A. F.; Gibaja, J. F. y Gavilán, B. 2012: “Technologie, typologie et analyses fonctionnelles de l'outillage lithique durant le néolithique Ancien dans la Cueva de Murciélagos de Zuheros (Córdoba, Espagne): réflexions sur la Néolithisation du sud de la Péninsule Ibérique”. L'Anthropologie 116: 148-170.

https://doi.org/10.1016/j.anthro.2012.02.001

Castañeda, N. 2014: El trabajo del sílex. La mina del Neolítico Antiguo de Casa Montero (Madrid) y su Sistema técnico. Tesis Doctoral. Universidad Complutense de Madrid. http://hdl.handle.net/10486/661865 (consulta 05-03-2017)

Castro, L. 1990: "Sobre la función simbólica del adorno". Brigantium 6: 93-99.

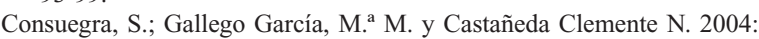
"Minería neolítica de sílex de Casa Montero (Vicálvaro, Madrid)". Trabajos de Prehistoria 61(2): 127-140. https://doi.org/10.3989/tp.2004.v61.i2.47.

Fromont, N. 2013: Anneaux et cultures du Néolithique ancien: production, circulation et utilisation entre massifs ardennais et armoricain. British Archaeological Reports, International Series 2499, Archaeopress. Oxford.

Fromont, N.; Maingaud, A.; Coutard, S.; Leclerc, G.; Bohard, B.; Thomas, Y. y Charraud, F. 2006: "Un site d'acquisition du schiste pour la fabrication d'anneaux au Néolithique ancien à Saint Germain-du-Corbéis 'l'Ermitage' (Orne)". Bulletin de la Société préhistorique française 103 (1): 49-70. https://doi.org/10.3406/bspf.2006.13395

Goñi Quinteiro, A.; Rodríguez Rodríguez, A. M.; Camalich Massieu, D.; Martín Socas, D. y Francisco Ortega, M. I. 1999: "La tecnología de los elementos de adorno personal en materias minerales durante el Neolítico Medio. El ejemplo del poblado de Cabecicos Negros (Almería)". En J. Bernabeu Aubán y T. Orozco Köhler (eds.): II Congrés del Neolitic a la Península Ibèrica (Valencia 1999). Sagvntvum Plav Extra 2, Universitat de València. València: 163-170.

Holgate, R. 1995: "Neolithic Flint mining in Britain". En J. Lech (ed.): Archaeologia Polona 33. Special theme: flint mining. Dedicated to the Seventh International Flint Symposium. Warsaw: 133-161.

Lozano Rodríguez, J. A.; Puga Rodríguez, E.; García-Casco, A.; Martínez-Sevilla, F.; Contreras Cortés, F.; Carrasco Rus, J. y MartínAlgarra, A. 2017: "First evidence of prehistoric eclogite quarrying for polished tools and their circulation on the Iberian Peninsula". Geoarchaeology 33 (3): 364-385. https://doi.org/10.1002/gea.21646

Martín-Socas, D.; Camalich Massieu, M. D.; Caro Herrero, J. L y Rodríguez-Santos, F. J. 2018: "The beginning of the Neolithic in Andalusia". Quaternary International 470B (20): 451-471. https://doi.org/10.1016/j.quaint.2017.06.057

Martínez Sánchez, C. 1994: "Nueva datación de C-14 para el Neolítico de Murcia: Los Abrigos del Pozo (Calasparra)". Trabajos de Prehistoria 52: 157-161. https://doi.org/10.3989/tp.1994.v51.i1.481.

Martínez-Sevilla, F. 2010: "Un taller neolítico de brazaletes de piedra en la cueva de los Mármoles (Priego de Córdoba)". Antiquitas 22: 35-55.

Martínez-Sevilla, F. 2013: "La tecnología de elaboración de los brazaletes anchos de piedra neolíticos del sur de la Península Ibérica”. En A. Palomo, R. Piqué, y X. Terradas (eds.): Experimentación en arqueología. Estudio y difusión del pasado. Sèrie Monogràfica del Museu d'Aqueologia de Catalunya. Girona: 87-96.

Martínez-Sevilla, F. 2014: "Los contextos de producción de brazaletes de piedra neolíticos en el Sur de la Península Ibérica y sus implicaciones socioeconómicas". En II Congreso de Prehistoria de Andalucía (Antequera, Málaga 2012): 303- 313. Antequera

Martínez-Sevilla, F. 2016: Un adorno reflejo de una sociedad. Los brazaletes líticos del Neolítico de Iberia (VI-V milenio a.C.). Tecnología, funcionalidad y circulación. Tesis Doctoral. Universidad de Granada. http://0-hera.ugr.es.adrastea.ugr.es/tesisugr/26513481.pdf (consulta 03-05-2017).

Martínez-Sevilla, F.; Morgado, A.; Jiménez Cobos, F.; Gutiérrez Rodríguez, M.; López García, A.; Lozano, J. A. y Carrasco Rus, J. 2016: "Knapping methods and techniques in the bracelets quarry of Cortijo 
Cevico (Loja, Granada)". Journal of Lithic Studies 3 (2): 45-65. https://doi.org/10.2218/j1s.v3i2.1450

Martínez-Sevilla, F. y Salmerón Juan, J. 2014: "La artesanía de los brazaletes líticos de la Cueva-Sima de la Serreta (Cieza, Murcia) tecnología, útiles y funcionalidad del sitio". Zephyrus 74: 65-87. https://doi.org/10.14201/zephyrus2014746587

Molina González, F.; Cámara Serrano, J. A.; Afonso Marrero, J. A.; Martínez Fernández, G.; Gámiz Caro, J. y Capel Martínez, J. 2017: "Hiatus in archeological multilevel site: Los Castillejos in Las Peñas de los Gitanos (Montefrío, Granada)". En A. Angelini y M. Cupitó (eds.): Beyond Limits: Studi in onore di Giovanni Leonardi. Padova. Università degli Studi di Padova, Antenor Quaderni 39. Padova: 91-100.

Montero Ruíz, I. y Ruíz Taboada, A. 1996: "Enterramiento colectivo y metalurgia en el yacimiento neolítico de Cerro Virtud (Cuevas de Almanzora, Almería)". Trabajos de Prehistoria 53 (2): 55-75. https://doi.org/10.3989/tp.1996.v53.i2.392

Morgado, A. y Lozano, J. A. 2011: "La explotación prehistórica de afloramientos de rocas ofíticas del sector oriental del Trías de Antequera (España): un patrimonio natural y cultural a valorar y proteger". En A. Peinado (ed.): Actas del I Congreso Internacional el patrimonio cultural y natural como motor de desarrollo: investigación innovación (Jaén 2011): 1503-1517. Jaén.

Morgado, A.; Lozano, J. A. y Pelegrin, J. 2011: "Las explotaciones prehistóricas del sílex de la Formación Milanos (Granada, España)". Menga 2: 135-155.

Morgado, A; Martínez-Sevilla, F. y Lozano, J.A. 2013: "Tallar para pulir. Experimentación sobre la elaboración de hachas pulimentadas de rocas ofíticas en el sur de la península ibérica”. En A. Palomo, R. Piqué y X. Terradas (eds.): Experimentación en arqueología. Estudio y difusión del pasado. Sèrie Monogràfica del Museu arqueologia de Catalunya. Girona: 109-118.

Pailler, Y. 2007: Des dernières industries à trapèzes à l'affirmation du Néolithique en Bretagne occidentale (5500-3500 av. J.-C.). British Archaeological Reports, International Series 1648, Archaeopress. Oxford.

Pellicer Catalán, M. y Acosta Martínez, P. 1997: El Neolítico y Calcolítico de la Cueva de Nerja en el contexto andaluz. Trabajos sobre la Cueva de Nerja 6, Patronato de la Cueva de Nerja. Málaga.

Peña-Chocarro, L.; Pérez Jordà, G.; Morales Mateos, J. y Vera Rodríguez, J. A. 2013: “ . . y llegaron los agricultores: agricultura y recolección en el occidente del Mediterráneo". Menga 4: 15-33.
Pérez-Valera, F. 2005: Estratigrafía y tectónica del Triásico Subibérico en el sector oriental de la Cordillera Bética. Tesis Doctoral. Universidad de Granada. http://hdl.handle.net/10481/643 (consulta 05-03-2017)

Pétrequin, P.; Cassen, S.; Chevillot, C.; Errera, M.; Pailler, Y.; Pétrequin, A.-M.... y Prodéo, F. 2015: "La production des anneaux-disques alpins pendant les VI et V millénaires a.v, J.-C. et Le Mont Viso". En P-J. Rey y A. Dumont (eds.): L'homme et son environnement: des lacs, des montagnes et des rivières. $40^{\mathrm{e} m e}$ supplément à la Revue Archéologique de 1'Est. Dijon: 259-302.

Pétrequin, P.; Pétrequin, A-M.; Pailler, Y.; Buthod-Ruffier, D.; Cassen, S.; Eibl, F.... y Prodéo, F. 2017: "Les anneaux-disques réguliers à section triangulare en jade ou en serpentinite". En P. Pétrequin, E. Gauthier y A.-M. Pétrequin (eds.): JADE objets-signes et interpretations sociales des jades alpins dans l'Europe néolithique 3. Presses universitaires de Franch-Comté y Centre de recherche archéologique de la vallée de 1'Ain: 611-638.

Reimer, P. J.; Bard, E.; Bayliss, A.; Beck, J. W.; Blackwell, P. G.; Bronk Ramsey, C.... y Van Der Plicht, J. 2013: "IntCal13 and Marine13 Radiocarbon Age Calibration Curves 0-50,000 Years cal BP". Radiocarbon 55 (4): 1869-1887.

Ruíz Taboada, A. y Montero, I. 1999: "Ocupaciones neolíticas en Cerro Virtud: estratigrafía y dataciones”. En J. Bernabeu Aubán y T. Orozco Köhle (eds.): II Congrés del Neolític a la Península Ibèrica (Valencia 1999). Saguntum-Plav Extra 2. Universitat de València. València: 207-211.

Sanz de Galdeano, C.; Lozano, J. A y Puga Rodríguez, E. 2008: "El 'Trías de Antequera': naturaleza, origen y estructura". Revista de la Sociedad Geológica de España 21 (3-4): 111-124.

Terán Manrique, J. y Morgado, A. 2011: "El aprovechamiento prehistórico de sal en la Alta Andalucía. El caso de Fuente Camacho (Loja, Granada)". Cuadernos de Prehistoria y Arqueología de la Universidad de Granada 21: 213-242.

Vera Rodríguez, J. C y Martínez Fernández, M. 2012: "El contexto de la producción y circulación de cerámicas y elementos de adorno en el Neolítico Antiguo del sur de Córdoba". Rubricatum 5: 273-280.

Vicent, A. M. y Muñoz Amilibia, A. M. 1973: Segunda campaña de excavaciones La cueva de Los Murciélagos, Zuheros (Córdoba) 1969. Excavaciones Arqueológicas en España 77. Ministerio de Cultura. Madrid. 